\title{
PROCESS-BASED IDEOLOGY OF PARTICIPATIVE EXPERIMENTATION TO FOSTER IDENTITY-CHALLENGING INNOVATIONS: THE CASE OF GMAIL AND ADSENSE
}

\author{
Raghu Garud* \\ Pennsylvania State University \\ Smeal College of Business \\ 431 Business Building \\ University Park, PA 16802 \\ $+1(814) 863-4534$ \\ rgarud@psu.edu
}

\author{
Arvind Karunakaran \\ Massachusetts Institute of Technology \\ Sloan School of Management \\ 100 Main Street, Room E62-383 \\ Cambridge, MA 02142 USA \\ +1 (814) 206-4189 \\ arvindk@mit.edu
}

Keywords: Identity, Ideology, Innovations, Process, Google

${ }^{*}$ This paper is a collaborative effort as reflected in the alphabetical ordering of authorship. We thank Ann Langley and anonymous reviewers for their valuable comments on an earlier version of this paper. 


\title{
PROCESS-BASED IDEOLOGY OF PARTICIPATIVE EXPERIMENTATION TO FOSTER IDENTITY-CHALLENGING INNOVATIONS: THE CASE OF GMAIL AND ADSENSE
}

\begin{abstract}
Prior research has examined how organizational identity can enable and constrain innovations. A complementary literature has examined organizational ideology as the basis for actions driving identity-enhancing innovations. We examine how organizational ideology can serve as the basis for identity-challenging innovations through an in-depth study of the emergence of two innovations at Google-Gmail and AdSense. Findings from this study highlight a process-based ideology of participative experimentation. We explicate the constituent elements of this process-based ideology, and discuss its implications for research on innovation and identity.
\end{abstract}




\section{INTRODUCTION}

How might organizations enable innovations that challenge their identities? Motivating this question is the importance of cultivating innovations within organizations operating in dynamic environments characterized by discontinuous change. To survive, firms must proactively introduce discontinuous innovations before others. However, generating organizational support for discontinuous innovations is difficult, as such innovations threaten an organization's identity (Anthony and Tripsas, 2016; Tripsas, 2009).

To answer the question posed, we conducted an in-depth study of two identitychallenging innovations at Google-Gmail and AdSense. Data analysis led to the identification of three mechanisms that enabled identity-challenging innovations at Google. The first is reflection-through-action, which is based on the integration of thinking with doing. The second is prototyping, which enables the materialization of nascent ideas. The third is collective engagement, which occurs in public forums set up for demonstrating, sharing, and refining ideas.

Together, these mechanisms constitute an organizational ideology of participative experimentation. Participative experimentation is a process-based ideology where "processes are more fundamental than things" (Rescher, 1996:28). Specifically, Google employees used technologies that were not in favor in order to develop the two identity-challenging innovations we describe in this paper. These innovations, along with other such identity-challenging innovations, resulted in the reconfiguration of Google's identity, which at that time was anchored around web search.

To develop these points, we first review the literature on identity and innovations, and complement it with research on organizational ideology as the basis for action. Second, we describe the methods that we used to gather and analyze the data. Third, we provide an account 
of what transpired during the emergence of Gmail and AdSense, and theorize how a processbased ideology of participative experimentation facilitates identity-challenging innovations. We conclude the paper by discussing the implications of this study for research on innovation and identity, and highlight the boundary conditions for the transferability of the findings from this study.

\section{BACKGROUND}

From the vast literature on organizational identity (see Gioia, Patvardhan, Hamilton, and Corley, 2013; Hernes and Schultz, 2017), we summarize the literature on identity that is relevant to innovation (e.g., Anthony and Tripsas, 2016; Ravasi and Schultz, 2006; Tripsas, 2009). Subsequently, we explore organizational ideology as the basis for action in the context of innovation (e.g., Brunsson, 1982; Zammuto, Gifford and Goodman, 2000). Based on this review, we revisit the research question that we posed earlier.

\section{Organizational Identity and Innovation}

There is increasing interest among management scholars on the role that organizational identity plays in enabling and constraining innovations (Fiol, 2002; Tripsas 2009; Schultz and Hernes, 2013). Organizational identity is defined as a collective sense amongst organizational members as to "who we are" as an organization (Gioia and Hamilton, 2016). In turn, "who we are" holds implications for "what we do," including the kinds of innovations that a company pursues over time (Nag, Gioia, and Corley, 2007; Ravasi, Tripsas, and Langley, 2017; Tripsas 2009; Schultz and Hernes, 2013).

Recently, Anthony and Tripsas (2016) proposed an identity-based categorization of innovation - identity-enhancing, identity-stretching, and identity-challenging. In the case of identity-enhancing innovations, there is a mutually constitutive relationship between identity and 
innovation, wherein "identity guides innovation, and innovation reinforces identity" (Anthony and Tripsas, 2016: 420). For instance, Nokia employees forged an organizational identity around affordable Global System for Mobile (GSM) phones, which in turn informed innovations that unfolded at the company (Vuori and Huy, 2016).

Innovations that do not neatly fit into an organization's identity but instead stretch it fall into a second category. For instance, Ravasi and Schultz (2006) described the emergence of an identity-stretching innovation at Bang \& Olufsen. In contrast to Nokia, Bang \& Olufsen began pursuing high-end product designs that combined technical excellence with emotional appeal when they confronted market competition and shifts in consumer tastes (see also Ravasi and Phillips, 2011). The company also changed its distribution channel by displaying its identitystretching innovations in exclusive stores and 'mini-shops' within high-end departmental stores. Identity-challenging innovations constitute a third category. Because identity acts as a cognitive filter, the employees of an organization may not even recognize innovations that challenge the organization's identity. Such innovations, even if proposed by someone, will be considered illegitimate by others including top management (Dougherty and Heller, 1994). As a result, these identity-challenging innovations find it difficult to garner the necessary resources for further development, and so may not even emerge.

For instance, Tripsas (2009) described how employees at Linco did not appreciate the value of flash memory, an identity-challenging innovation, because they thought of Linco as a digital photography company making digital memory cards. Consequently, Linco employees did not redevelop the company's digital memory cards into USB flash drives until it was too late. In Nokia's case, managers did not voice concerns when Apple introduced the iPhone with its powerful iOS operating system, because Nokia's identity was anchored around mobile phones 
and not the operating system. Moreover, fearing a loss of social status, Nokia managers did not speak up for a need to change Nokia's course of action (Vuori and Huy, 2016). The pluralistic silence that ensued, along with a 'not invented here' culture, led to the company focusing attention on its existing Symbian operating system rather than on the development of an identitychallenging innovation i.e., a smartphone-centric operating system that could compete with Apple's iOS operating system.

As the examples highlight, a company's inability to pursue identity-challenging innovations can prove costly. This begs the question as to how organizations might enable identity-challenging innovations. To address this question, we studied the emergence of two identity-challenging innovations at Google. Before reporting on the findings, we first examine prior research on organizational ideology as the basis for generating commitment to actions driving innovations within organizations (e.g., Brunsson, 1982).

\section{Organizational Ideology and Innovation}

While the literature establishing the relationship between identity and innovation has been growing, a complementary literature on organizational ideology has remained underexplored (e.g., Beyer, Dunbar, and Meyer, 1988; Brunsson, 1982; Fine and Sandstorm, 1993; Zammuto, Gifford and Goodman, 2000). Fine and Sandstorm (1993: 24) defined ideology as "a set of interconnected beliefs and their associated attitudes." In the organizational realm, Beyer and Trice (1981:166) introduced organizational ideology as "relatively coherent sets of beliefs that bind some people together and that explain their worlds in terms of cause-and-effect relations." In a similar vein, Brunsson noted that ideas shared by all organizational members afford a "common bases for discussion and action" (1982:38). ${ }^{1}$

${ }^{1}$ The concept of organizational ideology is closely related to the concept of organizational culture (Hatch, Schultz, and Skov, 2015; Zammuto, Gifford and Goodman, 2000). Zammuto and colleagues noted that 
Based on his research of an innovative company, Brunsson $(1976,1982)$ argued that a shared organizational ideology helps employees generate enthusiasm for their projects. Rather than decision irrationality arising from search and choice associated with decision-making, organizational ideology serves as the basis for engendering commitment amongst employees to a course of action. Such "action rationality" is particularly important in the case of innovations where decision-making is problematic given the "fog of reality" that exists (Brown, 1997).

An example is the commitment and enthusiasm generated amongst employees at $3 \mathrm{M}$ Corporation for the design and development of single-channel cochlear implants (Garud and Van de Ven, 1992). Despite ambiguity, 3M's commitment to the development of single-channel implants was reinforced by employees' shared beliefs about the benefits to the profoundly deaf from single-channel cochlear implants. In particular, they believed that single-channel implants would provide the deaf a sensation of environmental sounds while inflicting the least amount of trauma to the cochlea (Garud and Rappa, 1994).

However, organizational ideology as currently understood will likely foster identityenhancing rather than identity-challenging innovations. Organizational ideologies serve as "action generators" because collective beliefs and values become taken-for-granted, and so remain unquestioned (Starbuck, 1983). It is only when there is an exogenous shock (Meyer, 1982) that a firm is jolted out of its ideological reverie. Yet, by the time such shocks are experienced, the firm will find itself in an ideological flux, which makes it difficult for corrective actions to unfold (Brunsson, 1982). This was the case with Kodak, which entered into a tailspin making its survival difficult (Lucas and Goh, 2009).

the literature on culture defines culture broadly to include idiosyncratic organizational manifestations of beliefs in the form of myths, stories, rituals, structures, and that the actual substance of a culture resides in its ideology (Trice and Beyer, 1993, p 33). 
Identity-enhancing innovations are certainly useful for sustaining a firm's competitive advantage in stable environments. However, they are insufficient in and of themselves to help organizations navigate dynamic environments where firms' competitive advantages are threatened by discontinuous innovations. In such environments, firms must actively engage in identity-challenging innovations (Lynn, Morone and Paulson, 1996). Ironically, it is during periods of discontinuous change that organizational ideologies are in flux, a situation that dampens action (Brunsson, 1982).

Based on these observations, we further refine our orienting question. Specifically, is there an organizational ideology that enables identity-challenging innovations within organizations? To address this question, we explored the emergence of two identity-challenging innovations at Google — Gmail and AdSense. We found that employees at Google valued a process-based ideology of participative experimentation over and above a substance-based ideology comprising actors with fixed identities and technologies with known functionalities (see Rescher, 1996 for a distinction between "process" and "substance"). The innovations that emerged from participative experimentation reconfigured Google's identity over time.

\section{RESEARCH DESIGN AND METHODS}

Emulating studies in strategy and innovation that have used historical methods (Hargadon and Douglas, 2001; Kahl, Silverman and Cusumano, 2012; Murmann, 2012) to analyze exemplary cases (e.g. Danneels, 2011; Joseph and Ocasio, 2012; Siggelkow, 2002), we conducted a qualitative case study of Project Caribou at Google that led to two identitychallenging innovations. The case study approach is particularly useful for conducting longitudinal analysis (Burgelman, 2011; Langley, Smallman, Tsoukas and Van de Ven, 2013) to refine existing theory (Tsoukas, 2009). We chose Google as it has been able to reconfigure its 
identity from 'search' to a 'platform of products and services' based on its innovations (Edelman and Eisenmann, 2010; Fast Company 2010; Businessweek, 2010; Hamel and Breen, 2007).

\section{Data Collection}

We gathered data from multiple sources (close to 600 in all) across three levels: project, organization, and industry (see Table 1). At the project level, we gathered data from a variety of sources, including official product blogs and personal blogs of project actors. These blogs and recorded audio and video interviews of the actors involved with Project Caribou served as a proxy for direct observations and live interviews. We also gathered multiple pre-launch screenshots of the product (i.e., Gmail) that Project Caribou had generated at various timeperiods of its development to help us understand the project's trajectory over time (Meyer, 1991). These served as a "real time digital trace" (Dunbar and Garud, 2009; Tuertscher, Garud, and Kumaraswamy, 2014) of the dynamics that ensued. ${ }^{2}$ The willingness of Marissa Mayer, one of Project Caribou's members, to publicly accept "embarrassing mistakes" (such as potentially shutting down a $\$ 2$ billion USD product line), strengthened the validity of the account.

-- Insert Table 1 here --

At the organizational level, we gathered data from different archival sources including annual reports, reports from financial analysts, SEC filings, and several academic articles and case studies (Edelman and Eisenmann, 2010; Groysberg, Thomas, and Wagonfeld, 2009; Hamel and Breen, 2007; Hild and Mitchell, 2004; Iyer and Davenport, 2008; Page, 2004; Rindova, Yeow, Martins and Faraj, 2012; Yegge, 2006). We also referred to books written about Google's history, culture, and work practices (Battelle, 2005; Girard, 2009; Levy, 2011; Schmidt and Rosenberg, 2014; Stross, 2008; Vise and Malseed, 2007) and visited websites of company

\footnotetext{
${ }^{2}$ For the Gmail pre-launch prototypes, see http://techcrunch.com/2008/06/06/the-evolution-of-pre-launch-gmail-in$\underline{\text { screenshots }}$
} 
watchdog organizations such as insidegoogle.com. We used several databases (ABI Inform, Business Source Premier, Lexis-Nexis Academic, and Information Sciences Abstract) to identify articles on Google using a combination of keywords: 'Google,' 'Google Inc.,' and 'GOOG.' These press releases offered a chronology of events in Google's history. We also benefitted from extensive prior historical work (e.g., Battelle, 2005) and video documentaries on Google. In addition, Google has made publicly available a vast array of self-reported information in the form of articles, videos, and technical reports that provide insights into their internal work culture, practices, and technologies.

At the industry level, we gathered reports from Gartner, Forrester, IBIS World, International Data Corporation (IDC), S\&P's NetAdvantage, and searchenginewatch.com. Specifically, we looked for data that would help us understand the technological field following the dot-com crash when Project Caribou took shape. We also gathered information on the popular programming tools and frameworks of the time and the shared beliefs held by technology analysts and experts on the potential of these tools and frameworks and their thoughts about the future of the web and web programming.

These data allowed us to take a longitudinal multi-level perspective on the two innovations we studied as they unfolded. For instance, first person accounts of the actors involved with Gmail and AdSense offered an understanding of what transpired. Press releases, interviews with other top managers, documentaries, and case studies on Google presented us with a contextualized understanding of the processes that unfolded while unofficial blogs and interviews of Google employees conducted by others offered a more detailed view. Audio recordings of interviews with the product manager of Project Caribou complemented the interview accounts and blog posts of Project Caribou's technical lead. 


\section{Data Analysis}

Data collection and analysis unfolded iteratively (Miles and Huberman, 1984). First, we started by reading these data to gain a holistic perspective of Project Caribou, the company, and the industry at large (see Table 2 for an abbreviated chronology). By triangulating across these data (Jick, 1979), we identified the critical events (Van de Ven and Poole, 1990) underlying the processes that unfolded in each of the embedded cases. As Burgelman (2011: 594-599) noted, such historical methods involve "reconstructing the unfolding of individual and collective action patterns leading up to relatively unique events" and "to document the intersection of continuities and contingencies, and the effects of context on outcomes."

\section{-- Insert Table 2 Here --}

As the process unfolded, we wrote a longitudinal case detailing the emergence of Gmail and AdSense, the organizational beliefs and values at that time, and the industry context, so as to better understand the interconnections between the multiple strands of events that unfolded. The case writing went through multiple iterations, culminating in the generation of a case chronicling the genesis and development of Project Caribou. We discussed the case with several Google employees of different ranks (software engineers, technical architects, product managers, and user experience researchers) to confirm that it resonated with their work experiences. This step represents member check (Lincoln and Guba, 1986) to confirm the accuracy and adequacy of our efforts.

We also engaged in a process of "constant comparison" (Glaser, 1965) to identify emerging themes relevant to our research question on the mechanisms that enable identitychallenging innovations. "Initial coding" (Charmaz, 2006) involved identifying and bracketing "in vivo" codes from the data. During this process, additional questions emerged (Strauss and 
Corbin, 1998): How did Google, a search engine company, come up with so many products that were not directly related to search? How did the company's capabilities change over time? What were the popular tools, technologies and programming languages pre- and post- dot-com crash?

Addressing these questions drew our attention to missing pieces of data, which led to additional rounds of data collection and analyses. As we revisited the data, we employed "focused coding" (Charmaz, 2006) to articulate second-order themes. Subsequently, we engaged in "theoretical coding" (Charmaz, 2006) by aggregating these themes into the three overarching mechanisms. We also provide supporting evidence from the rest of Google on the prevalence of these mechanisms.

We report the findings from this study in two steps. First, we provide a narrative account to explicate the dynamics that ensued within Project Caribou (Langely, 1999; Van de Ven and Poole, 2005; Tsoukas and Hatch, 2001). A narrative account allows for the temporal ordering of events that simultaneously implicates "the physical artifacts (e.g., equipment, databases and documents), work processes (e.g., analytic techniques and standard operating procedures), and people (e.g., expertise, power and political clout)" involved (Bartel and Garud, 2009). While providing contextual details, narratives also help identify underlying generative mechanisms that can be applied from one setting to another. Second, we identify the mechanisms enabling identity-challenging innovations at Google and "theorize the arrows" (Langley, 1999) to explicate interactions between them. This step culminated in a model of how firms can enable identity-challenging innovation through a process-based organizational ideology of participative experimentation.

GOOGLE AND PROJECT CARIBOU 
On April 1, 2004, Google's press release included two items that generated considerable discussion. First, Google announced its plans to open an Offshoring center on the moon by the year 2007. The center was publicized as a fully integrated research, development and technology facility for conducting experiments in an "entropized high-density high-delivery hosting (HiDeHiDeHo) and de-oxygenated cubicle dwelling" (Google, 2004a). Second, Google proposed a launch of the free web-based email service called Gmail. This was promoted as "an email service that has no 'delete' button, with 1GB of storage and with absolutely no pop-ups and banners" (Google, 2004b).

Google was known for its April Fools' Day pranks, such as PigeonRank. ${ }^{3}$ This time, however, people weren't sure which of the two announcements was an actual prank. Analysts and technology enthusiasts began digging through previous reports, press releases, and interviews of Google's leaders to understand what was going on. One analyst uncovered a 1999 interview with Larry Page (co-founder of Google) and posted the following excerpt:

I won't say we won't add services, but we wouldn't put free email on our site unless we thought we could do a much better job. If we add random services, we don't think that adds value... Our goal is to produce no holds barred, the best search available. (Page, as quoted in Sullivan, 1999)

Given that Google's identity was that of a 'search engine', many had already concluded that the company's announcement of Gmail was an April Fool's Day prank (BBC, 2004; Slashdot, 2004; Sullivan, 2004). The posting quoted above further strengthened this conclusion, as most of Google's revenue at that time came from the licensing of its search technology to other portals. In fact, its very name had become synonymous with the search for information available on the World Wide Web.

\footnotetext{
${ }^{3}$ PigeonRank was an April Fool's Day prank, proposed as a system for computing the relative value of web pages with the help of pigeons. See https://archive.google.com/pigeonrank/
} 
However, on April 25, 2004, Google began sending out Gmail invites to a select group of bloggers. These bloggers were given the option to send out additional invites to their networks of friends and trusted sources. In this way, Gmail began spreading rapidly, resulting in PC World magazine ranking Gmail as the second best product of 2005. Gmail's features, including its 1GB of free storage, conversation view, and asynchronous email access, began gaining a lot of traction amongst its user base, which grew by 43 percent from 20.8 million to 29.6 million between December 2007 and December 2008. In the meantime, Google also built capabilities using AJAX, a development technique for building rich internet applications, which in turn enabled the company to establish a competitive advantage in the second-generation of web applications (i.e., Web 2.0). Through AdSense, a product that emerged during the process of monetizing Gmail, Google created a new business model that brought advertisers and content providers together, accounting for more than 30 percent of Google's revenues. We now recount the events that transpired in the emergence of Gmail and AdSense from Project Caribou.

\section{Gmail}

According to Larry Page, the genesis of the idea to develop an email application can be traced to an email sent by a Google employee who complained about the poor quality of existing email services. He reported:

She kvetched [sic] about spending all her time filing messages or trying to find them. And when she's not doing that, she has to delete email like crazy to stay under the obligatory four megabyte limit. So she asked, 'Can't you people fix this?' (Google, 2004b)

The question raised by the employee set off a conversation within Google about the pros and cons of existing email platforms. At that time, employees at Google were unsure about developing yet another email product amidst a plethora of other free services. Microsoft, Yahoo!, and AOL already dominated the market for web-based email, with Microsoft's Hotmail boasting 
an active-user base of 170 million. The internal conversation on the pros and cons of developing an email product caught the attention of Paul Buchheit, a Google employee who was finishing a project that is now referred to as Google Groups. Prior to joining Google, Buchheit had worked on a web-based email application that could be accessed from anywhere. Although he had written some code, "it was never useful and never got off the ground" and the project "didn't go anywhere" (Buchheit, as quoted in Livingston, 2007). Given his prior interest, Buchheit offered to build a web-based email product. But his idea was not received positively. Buchheit later noted:

This was when Google was still pretty much thought of as exclusively search, so even the idea of doing something like email was strange... It was really kind of the first thing that diverged from the simple idea of web search. Even Groups [Google Groups] is still basically search - it's just search over public Usenet posts... So it took a while for people to get used to the idea of something different [from search]. (Livingston, 2007)

Though it may seem obvious today, the benefits of Google entering email services were not as clear at that time. Google's identity around 'search' was an important factor. This organizational identity, empowering the company during its early stages of development, now shaped the perspectives of those within Google about potential avenues for growth. Efforts and actions that diverged from Google's focus on search were viewed with suspicion. Developmental efforts could have been easily blocked because of these blinders.

Instead of seeking formal approval from top management, Buchheit decided to develop a prototype by reusing code he had written earlier. No one at Google was clear about the attributes of the product to be developed, as user preferences had yet to emerge. Buchheit's immediate superiors were "very general—just kind of saying, 'Yeah, we think there's something interesting to do here', but it wasn't like they gave me a list of features. People really weren't sure what it was" (Buchheit, as quoted in Livingston, 2007). 
Rather than representing a clear-cut decision point, the genesis of Gmail (later developed within a project labeled as Caribou $)^{4}$ was tentative. Challenges associated with such tentative starts include the mobilization of support and resources, especially for projects that are identitychallenging. Since Project Caribou was not a run-of-the-mill project with clear-cut outcomes that could be showcased to relevant stakeholders within a stipulated period of time, why did it survive? Below, we describe the dynamics that ensued.

Making the case. As Project Caribou progressed, questions continued circulating within Google seeking justifications for diverging from search. Google employees were skeptical about the utility of another email product while popular email applications already existed. Consequently, top management was reluctant to allocate resources to the project. Buchheit (2009b) noted:

We starting [sic] working on Gmail in August (or September?) 2001. For a long time, almost everyone disliked it... For quite a while, it was just myself; and then another person, Sanjeev Singh, started working on it. [T] hen later on another person, Jing Lim, started. It was a very slow kind of progression. And people were still a little bit uncertain about the whole idea of doing something as different as email... There are a variety of dimensions to the darkest days. Like I said, a lot of times it was sort of controversial, especially in the very early days, because people weren't sure if we should even be doing this. So the general attitude would swing, and then it would swing against us, that was very hard to deal with.

As Buchheit observed, the idea of developing an email application within a company

focused on search had little legitimacy. To gain legitimacy, project members engaged in

interactions with colleagues as described by Buchheit (2005):

We had a lot of ideas, but first we spent a lot of time talking to all kinds of people about their email. They let us watch over their shoulders and helped us really understand how they use email and what they need from it. We didn't want to simply bolt new features onto old interfaces. We needed to rethink email, but at the same time we needed to respect that email already had over 30 years of history, thousands of existing programs, and nearly a billion users. So we started

\footnotetext{
${ }^{4}$ Project Caribou is named after a reference in a Dilbert cartoon to a drawn-out, never-ending project.
} 
by learning which features were most important, and which problems were most aggravating.

Besides watching employees use the product and interacting with them, project members also empowered colleagues to find bugs and fix them. A Google engineer noted:

In my first month at Google, I complained to a friend on the Gmail team about a couple of small things that I disliked about Gmail. I expected him to point me to the bug database. But he told me to fix it myself, pointing me to a document on how to bring up the Gmail development environment on my workstation. The next day, my code was reviewed by Gmail engineers, and then I submitted it. A week later, my change was live. I was amazed by the freedom to work across teams, the ability to check in code [submit workable programs] to another project, the trust [placed] in engineers to work on the right thing, and the excitement and speed of getting things done for our users... I didn't have to ask for anyone's permission to work on this. (Quoted in Iyer and Davenport, 2008)

Inviting employees to become users of the product averted the political challenge of having to sell the identity-challenging innovation to others. Equally importantly, this step led to the expansion and refinement of the innovation itself. As people continually questioned, contested, and expanded the ideas, technologies and practices espoused by the project team, support for Project Caribou grew.

We did a lot of things wrong during the 2.5 years of pre-launch Gmail development, but one thing we did very right was to always have live code... Literally from day one, we had users internally. One nice thing about Google is that we can just release things internally and have this great population of testers, essentially... The great thing about this process was that I didn't need to sell anyone on my ideas. I would just write the code, release the feature, and watch the response. From that day until launch, every new feature went live immediately, and most new ideas were implemented as soon as possible. This resulted in a lot of churn - we re-wrote the frontend about six times and the backend three times by launch - but it meant that we had direct experience with all of the features. A lot of features seemed like great ideas, until we tried them. Other things seemed like they would be big problems or very confusing, but once they were in we forgot all about the theoretical problems. (Buchheit, 2009a)

Such co-creation processes enabled Project Caribou members to realize that email was more than a tool for communication; email could also serve as the basis for fostering ongoing 
conversations. Eventually, the idea that Project Caribou was creating a 'conversation platform' became its raison d'être.

“Not this crazy JavaScript stuff." Implementing email as a conversational platform required rethinking both the material and the social layers involved. One had to reconsider how emails could be stored, categorized, retrieved, and accessed instantaneously from the server to create an experience that resembled real-world ongoing conversations. The project team could have approached the problem with the technologies already in use at Google to gain legitimacy (Dougherty and Heller, 1994). However, there were costs associated with pursuing this option. Technologies used for developing search engines could easily constrain the development of an email application, which posed a new set of technical challenges. Unlike search engines that exhibit a time lag between crawling/indexing web pages and displaying search results, email applications must send, receive, and display emails without any time lag. One cannot say, "Well, we receive email and then in half an hour it will appear" (Buchheit, as quoted in Livingston, 2007). In other words, the use of existing techniques and tools would restrict the implementation of the application from resembling real-world conversations.

To address these issues, the project team decided to try JavaScript, a prominent clientside scripting language. Specifically, they invoked the little known "XmlHttpRequest" (XHR) object, a dormant Application Programming Interface (API) developed by Microsoft to retrieve and exchange emails between its Internet Explorer browser and the server asynchronously (i.e., without interfering with the display or requiring full-page reloads).

At that time, the use of JavaScript for building such complex, scale-intensive applications was considered taboo within Google. JavaScript, originally developed with the intention of helping web authors and amateurs make their pages more dynamic, was mostly used at that time 
as a client-side scripting language for web pages. Consequently, Google refrained from using JavaScript. In addition, JavaScript was associated with pop-up ads, especially those with pornographic content. To focus users' attention on search, Google's founders (Brin and Page, 1998) were against the use of pop-up ads. ${ }^{5}$

For all these reasons, the use of JavaScript was considered taboo at Google, which created problems for Project Caribou.

Quite a few people thought that we should kill the project, or perhaps 'reboot' it as an enterprise product with native client software, not this crazy JavaScript stuff... The JavaScript was a big deal as well, because at the time that we first started doing the interface in JavaScript, most people thought of JavaScript as a tool for pop-up advertising and other obnoxious things like that. This was before the whole Ajax thing, so a lot of people were pretty skeptical that JavaScript could work reliably. (Buchheit, 2009b)

Prototypes as persuasive arguments. Many organizations have formal processes to evaluate new initiatives (e.g., Cooper's (1990) stage-gate process). If JavaScript had gone through a formal approval process, managers could well have shut down the project given their experiences, beliefs, and values. Rather than seek formal approval, Buchheit wrote a quick-anddirty prototype that illustrated the rationale for using JavaScript.

The first version of Gmail was literally written in a day. It wasn't very impressive - all I did was take the Google Groups (Usenet search) code (my previous project) and stuff my email into it - but it was live and people could use it (to search my mail)... I actually started out with some of the Groups code, just because I was familiar with it... I released that to some Googlers and people said it was useful, so it progressed from there. (Buchheit, 2009a)

Although written in a day, the initial prototype demonstrated the possibility of weaving fragmented email responses together into one conversational thread. At that time, emails were not designed to aggregate responses in that way.

I was actually surprised to some extent at how positively some of the things we did were received. We were pretty nervous about some of our features. The idea

${ }^{5}$ http://www.google.com/corporate/ux.html 
of doing the whole thing in JavaScript - internally a lot of people were very unsure about that, but I think that our users loved it. It actually worked better than we expected it to. We were pretty nervous about it, because there are so many browsers out there and they all have plug-ins and some of these plug-ins will cause problems for you. It's really worked out better than we thought it would. (Buchheit, as quoted in Livingston, 2007)

Subsequent versions of the prototype expanded on this concept, and made the case for using JavaScript even stronger. The prototype borrowed the notion of 'threaded conversations' from Google Groups, Buchheit's previous project, and applied it to email. Similar to the organization of group-based discussions under a single thread, conversation among several parties would be threaded. ${ }^{6}$ To prevent the fragmentation of a thread, the prototype tracked all past conversations, and consolidated them under a single thread based on the subject header. All of these features required asynchronously obtaining data from the server, strengthening the case for using JavaScript. Subsequent versions of the prototype expanded this concept even more, further solidifying JavaScript as the technology to be used for developing an email application (refer to Hendrickson (2008) for screenshots of these prototypes). ${ }^{7}$

Reflecting on the efficacy of using code to demonstrate the value of an initiative, Buchheit (2009a) noted:

The point of this story is that you should consider spending less time talking, and more time prototyping, especially if you're not very good at talking or PowerPoint. Your code can be a very persuasive argument. The other point is that it's important to make prototyping new ideas, especially bad ideas, as fast and easy as possible.

The acceptance of JavaScript for building an email application grew as the prototype was deployed over Google's local area network (LAN). As internal users started using the prototype

\footnotetext{
${ }^{6}$ To understand this, consider a situation where A sends an email to B and C. B replies to A's message and copies C. Later, C replies to A's message and copies B. Now, when A replies to C's message, the conversation fragments as the email sent in-between A's original message and C's response by B will not be aggregated into the email thread.

${ }^{7}$ http://techcrunch.com/2008/06/06/the-evolution-of-pre-launch-gmail-in-screenshots
} 
for their own email, they began contesting, questioning and discussing its features. In addition, demonstrating the features and functionalities of the prototype via formalized sessions called demo slams that occur every week on Google campuses ensured that the rationale of utilizing JavaScript and XHR got increasing visibility. These sessions, in turn, enabled the Project Caribou team not only to legitimize the use of JavaScript for building the email application, but also to continually refine and improve it. In this way, the prototypes became the medium and outcomes through which distributed efforts surrounding the identity-challenging innovation were translated. They also shaped subsequent iterations of the idea in a more visual form, thereby enabling employees at Google to generate new options from a technology that deviated from the company's beliefs about the technologies at work.

Launch and subsequent improvements. Ready for launch in early 2004, the email application that emerged from Project Caribou was given a formal name-Gmail. The buzz that Google's April $1^{\text {st }}$ announcement generated drew the attention of many Internet users whose number has crossed a billion as of 2016. The Gmail team has steadily expanded the context of use by integrating chat (including group and video options), developing new anti-spam technology, shipping a mobile application, launching an iPhone user interface, integrating the application with Google Voice, enabling open protocols and APIs (POP, auto-forwarding, IMAP, and the Contacts Data API), and re-architecting their entire JavaScript code base. New features have been rolled-out continually with the help of Gmail Labs, which maintains a list of experimental new features that Google would like to explore. Unsure about their potential usefulness, Google allows users to decide which features are relevant. Users can enable and disable features as part of their everyday Gmail use, which Google tracks by analyzing logs and other real-time usage data. Features that are well received are integrated into the core product 
(e.g., Calendar, Maps, Task Lists, and Gmail Offline). Keith Coleman (2008), the Product

Manager of Gmail, noted:

People often ask how we decide what to build next. It's usually a mix of factors, like how many users are asking for it (think delete button, vacation responder, and IMAP, among others), how useful we think it will be (think chat, conversation view, etc.) or how much fun it will be to work on (this is actually really important). We have all sorts of debates about each option, we weigh the pros and cons, and then some of the time we probably make the wrong decision. Gmail Labs is a way for us to take lots of the ideas we wouldn't normally pick and let you all (who use Gmail) decide whether they're good or not.

As part of its efforts, Google has sought direct customer feedback using a standard webbased feedback form and user complaint emails, and narratives on how Gmail has changed user experiences. ${ }^{8}$ From the feedback they received $(1,500$ of them were short, one-minute video narratives), Google was able to roll-out innovative features that were personalized to user needs.

Since its inception, Gmail has become a huge success, fundamentally redefining email. Thus, the tagline of their April 1, 2004, press release, "Search is Number Two Online Activity Email is Number One" (Google, 2004b), has come true. A Financial Times article noted,

“Google has redefined e-mail. Microsoft and Yahoo! are starting to emphasize it once again, but it's been hard for them to keep up with Google's improvement" (Nuttall, 2009).

Innovative technique. As valuable as Gmail is, equally valuable is the expertise around the AJAX programming technique that Google developed in the process of creating Gmail. AJAX is an advancement of the technique that Gmail employed to asynchronously fetch and display data using the XmlHttpRequest (XHR) function and JavaScript. ${ }^{9}$ Before Gmail, industry participants had largely dismissed web-based applications, especially after the dot-com crash.

\footnotetext{
${ }^{8}$ See https://web.archive.org/web/20100213125427/http://www.google.com/mail/help/yourstory.html

${ }^{9}$ On February 18, 2005, almost 10 months after the initial launch of Gmail, Jesse James Garrett of Adaptive Path wrote an article titled 'Ajax: A New Approach to Web Applications,' summarizing the advancements in the web development space (i.e., using JavaScript along with the XHR function to asynchronously obtain data from web pages). He described this new approach as AJAX (Asynchronous JavaScript and XML).
} 
The common assumption was that web-based applications suffered from time lags and user engagement issues and that they could not match the speed and sophistication of desktop-based applications. However, Google's success with Gmail and later with Google Maps and other applications based on AJAX disabused industry actors of their beliefs. AJAX demonstrated that it was possible for web applications to have the look and feel of desktop applications. "Suddenly you've got a company like Google that has shown to a mass audience that rich Internet applications have a tremendous benefit to the end user," noted David Temkin (2005), chief technology officer of Laszlo Systems. "The difference between Google Maps and any other map site is not subtle - it's almost a different product category. And the same is true of Gmail." (Temkin, 2005, as quoted in the Wall Street Journal)

Realizing the potential of AJAX, Google actively sponsored the technology both inside and outside the organization. Within the organization, Google generated awareness about the potential of AJAX techniques to render web applications in a manner that was similar to desktop applications. To do so, they created an initiative that allowed employees to volunteer their time and create grouplets to facilitate awareness and learning. In this case, an AJAX grouplet was formed with the objective of diffusing AJAX programming techniques within the organization by creating tutorials, know-how documents, and other knowledge sharing tools.

Outside the organization, Google sponsored AJAX as a standard by releasing free development frameworks. In May 2005, it introduced a free development framework called Google Web Toolkit (GWT) for developing AJAX-based web applications. Later, in December 2006, Google open-sourced the toolkit that enabled programmers around the world to improve it by contributing code and adding more features. The result was a proliferation of comprehensive AJAX frameworks and libraries. Soon, a number of start-ups (e.g., Zimbra Inc., Joyent, Kiko, 
TrimPath, Upstartle) emerged that focused on building web applications exclusively by

leveraging the capabilities of AJAX. As Mangalindan and Buckman (2005) from the Wall Street

\section{Journal noted:}

The technique (i.e., AJAX) helps speed up computer operations by cutting down on the need to request fresh web pages from a distant server computer. Instead, AJAX applications can request smaller chunks of data to update a Web page already on a user's screen. As a result, Internet-based programs viewed inside Web browsers, such as instant messaging or email, can now behave more like bulkier software that resides on a desktop computer. Some of these Internet-based programs can also be cheaper to buy than desktop software, posing a potential threat to the likes of Microsoft's ubiquitous Office word-processing suite. (Mangalindan and Buckman, 2005)

By sponsoring AJAX as a web development technique, Google was able to generate innovative solutions to gain a competitive advantage over Yahoo! and Microsoft. In addition, the introduction of AJAX shook up the traditional desktop application market space (such as desktop-based email clients and word processors) and helped revitalize the Internet industry after the dot-com crash by paving the way for firms to move from Web 1.0 to Web 2.0. A technology (i.e., JavaScript) that deviated from Google's beliefs, and an innovation (i.e., Gmail) that challenged Google's identity led to the development and institutionalization of a programming technique (AJAX) that facilitated the growth and transformation of Google.

\section{AdSense}

During Gmail's development, Marissa Mayer, Google's product development manager, was tasked with creating a strategy to monetize the product. Standard industry practice at that time was to offer tiered mail services to users with limited free storage, and then charge for any additional storage (i.e. the 'freemium' model).

So, Paul and I shared an office...We were talking about, you know, how we (Google) may make money out of it. I was like, 'Oh, look, this is easy. We are going to have small mailboxes for free, and upsell them into larger mailboxes. That's what everybody does.' Paul was like, 'I'm not so sure. Maybe, we should put ads on Gmail.' I was like, 'Paul, Paul, Paul! Ads are never going to work. 
Because you know, either we run banner ads, and they're not going to be targeted, and people will develop blind-spots, and they're horrible in terms of effectiveness. And, you know, we will never make any money, and we will annoy our users. Or, we are going to target the ads at their email, which really sounds like creepy and weird... It's going to be terrible. Paul, there is no way.'... At 3 am, I remember leaving. I walk[ed] out of the door and lean[ed] back for a second and said, 'So Paul, we agree that we are not exploring the ad-thing again now, right?' And he was like, 'Yeah.' (Mayer, as quoted in Iinovate, 2007)

However, members of Project Caribou had other ideas. Sanjeev Singh kept pushing for the incorporation of relevant ads. Mayer was against the idea of putting ads into Gmail, as it was antithetical to Google's ideology that placed a primacy on "user experience." Since ads are intrusive, Mayer did not want any associated with Gmail. Moreover, she was influenced by the industry-wide freemium business model prevalent at that time.

Despite these misgivings on Mayer's part, Buchheit decided to prototype the idea to create contextual ads by connecting Gmail to Google's ads database. "I implemented this content-targeting system, just as a sort of side-project, not because I was supposed to... I hacked up the 'adult content' classifier that Matt Cutts and I had written for safe-search, linked that into the Gmail prototype, and then loaded the ads data into the classifier" (Buchheit, 2009a). In essence, he modified the classifier used to detect and classify adult content to connect ads with emails. When Mayer returned the next morning, she was surprised to find ads in her emails.

I leave and go home. I sleep for a couple of hours. I'm back in the office at 9. And I login to my email using Gmail in order to understand the problem of how it works. And I login to my Gmail. ADS EVERYWHERE. All over the place. And I was like, oh my god, I hate to tell Paul that. He was like up till 7'o clock doing the prototype. I was like should I call him and have him take it down? Because two of the other people who are using the email are Larry and Sergey. And Larry and Sergey, they have weird views of these ads and privacy. I thought, no, I am going to allow Paul to sleep for another hour at least, so that he gets couple of hours of sleep until I ask him to take the ads off. So, 9 o'clock...for the next one hour, I use the product. And I got an email from a friend who wants to go hiking. And, there was an ad for hiking boots. Al Gore was coming to visit the campus that day. And there were books about Al Gore advertised on the side. Once, you know, it looked possibly useful...so, by 10 o'clock, I no longer wanted Paul to take the 
ads down. And of course, Larry and Sergey came in at 11. And they were like, 'This is great.' (Mayer, as quoted in Iinovate, 2007)

This product later became AdSense (or, to be precise, 'Adsense for Content'), part of

Google's billion-dollar advertisement platform. Eventually, the notion of automated content-

targeted ads went on to become the world's largest advertising and search monetization program.

Mayer further reflected:

And that's when we had the observation of that day that this needn't have to be about email. That Paul's technique of finding those keywords and keyword lookup has evolved significantly so much... Something that would allow us to run the ads we ran on our search pages, and run them on any page on the web. And so, I said, ok, we are not sure if ads on Gmail are a good idea or not. But we do know that ads hugged to the content were a great idea... This story is a bit of... almost embarrassing to me because I almost shut down AdSense... So, Gmail spun the AdSense project. And of course, AdSense was a simpler project. That's how it got launched first. And Gmail got launched second... most people think that AdSense came before Gmail because that's what it looks from the outside... If you assume search is about $5 \%$ of web page views daily worldwide, which it roughly is, what AdSense did is it let ads on the other $95 \%$ of the page views. It really bought up our business multifold. (Mayer, as quoted in Iinovate, 2007) (emphasis added)

In this way, meaning emerged in action as actors engaged with one another and with the artifacts-at-hand, enabling them to turn identity-challenging ideas into a tangible product.

Buchheit reflected:

What I wrote was just a throwaway prototype, but it got people thinking because it proved that it was possible, and that it wasn't too hard because I was able to do it in less than a day. After that, other people took over and did all the hard work of making it into a real product... Of course, none of the code from my prototype ever made it near the real product (thankfully), but that code did something that fancy arguments couldn't do (at least not my fancy arguments), it showed that the idea and product had real potential. (As quoted in Livingston, 2007) (emphasis added)

AdSense was spun-out as a separate product and was launched in 2003, a full year ahead of Gmail. AdSense became a perfect complement to AdWords. AdWords enabled advertisers to buy space on Google's search results page, bid for keywords, and publish their Ads. AdSense, on 
the other hand, offered content providers a mechanism through which they could add advertising space to their websites. AdSense enabled Google to uncover and overcome another potential blinder by allowing targeted ads to be placed not just on its search results page, but also on websites, blogs, and other web applications. For the quarter ending March 31, 2010, the AdSense inspired business model generated revenues of \$2.04 billion, 30 percent of Google’s total revenue.

The processes that led to the emergence of two identity-challenging innovations (and an innovative programming technique) at Google were not aberrations. Other products and services such as Google News, Google Books and more have emerged in a similar fashion (see Hamel and Breen, 2007; Levy, 2011). Today, continual innovation has transformed the company from a search engine into a platform of products and services, ranging from web browsers to mobile operating systems.

\section{MECHANISMS ENABLING IDENTITY-CHALLENGING INNOVATIONS}

So far, we have offered a narrative account of the emergence of Gmail and AdSense. Our second-order analysis of the data revealed several mechanisms that made it possible for the emergence of these identity-challenging innovations. In this section, we introduce these mechanisms and discuss the interactions between them. Together, the three mechanisms enable a process-based organizational ideology of participative experimentation.

\section{Mechanisms}

The three mechanisms that we identified during our second order analysis are reflectionthrough-action, prototyping, and collective engagement. While these mechanisms were evident across the two innovations we studied, they appeared to be widespread across Google. We 
elaborate on each of these mechanisms, and provide supporting evidence for their prevalence across Google (Table 3).

\section{-- Insert Table 3 Here --}

Reflection-through-action. Prior work highlights the possibility of inaction when actors encounter ill-structured, ambiguous situations. For instance, Daft and Lengel (1986) noted that ambiguity could lead to action paralysis. In a similar vein, Denis, Dompierre, Langley, and Rouleau (2011) evoked the notion of "networks of indecision" leading to inaction in such situations. Such inaction is problematic for spawning innovations during early stages typically characterized by ambiguity (Garud and Van de Ven, 1992).

Rather than inaction, the Google case highlights an alternative mechanism: reflectionthrough-action. Confronting an ill-structured situation, Buchheit experimented to find out if something could be done to "thread" email conversations. Analogous to Weick's (1995) sentiments, "How can I know what I think until I see what I say?", Buchheit too could not say what would happen before he engaged in activities to see what would emerge, as expressed in his observation, which we reported before: "People really weren't sure what it was...It was a very slow kind of progression...I actually started out with some of the Groups code, just because I was familiar with it... I released that to some Googlers and people said it was useful, so it progressed from there."

Here, we connect with work on reflectivity developed by Schön $(1983: 268)$ who noted that practitioners develop "reflective conversations with the situation." Schön offered a distinction between reflection-in-action and reflection-on-action. The former is reflection while acting, whereas the latter is reflecting on the outcomes of actions. With respect to the former, it is clear from the data that actors actively framed situations they confronted by experimenting ("We 
didn't want to simply bolt new features onto old interfaces. We needed to rethink email...So we started by learning which features were most important, and which problems were most aggravating"). Reflecting-on-action is also evident in the data ("They let us watch over their shoulders and helped us really understand how they use email and what they need from it"). Overall, we use the term reflection-through-action to cover both facets of reflection that Schön introduced.

Google actively cultivates an organizational ideology that embraces reflection-throughaction. The company is known for its practices for hiring people with certain characteristics including a "bias for action" and "comfort with ambiguity" (Schmidt and Rosenberg, 2014:106, 121). ${ }^{10}$ According to Schmidt and Rosenberg (Google's top managers who played pivotal roles in shaping the company's ideology), these are the constitutive elements of "Googleyness" that the company looks for in its hires. Other facets of Googleyness are employees' creativity and their collaborative nature. Creativity and collaboration were readily evident in the prototypes that emerged and the collective engagement that ensued. We turn to these two mechanisms driving the bottom-up innovation processes at Google.

Prototyping. Prototyping is another mechanism evident in the Gmail and AdSense cases. Somewhere between ephemeral thought and stabilized artifacts, prototypes offer employees a way to showcase an idea even if language does not exist. Often based on bricolage (Levi Strauss, 1966), prototypes are quick and dirty working models to establish proof-of-concept. For instance, the initial version of the Gmail prototype was built in a day by experimenting with the already established Google Groups code base ("The first version of Gmail was literally written in a day. It wasn't very impressive.").

\footnotetext{
${ }^{10} \mathrm{We}$ thank an anonymous reviewer for directing our attention to this.
} 
Schrage (2000) noted that an organization's prototyping culture says a lot about its innovation capabilities. By allowing employees to develop incomplete working models rapidly, Google signaled that imperfect designs should not be considered as hopeless monstrosities, but instead as experimental probes instead (Lynn et al., 1996). For instance, the $1 \mathrm{~GB}$ of free storage space for Gmail emerged because of Google's capabilities around experimentation through prototyping. Marissa Mayer, Buchheit's supervisor, even thought she had an agreement with him (“So Paul, we agree that we are not exploring the ad-thing again now, right?”). However, Buchheit decided to prototype anyway, noting, "The point of this story is that you should consider spending less time talking, and more time prototyping, especially if you're not very good at talking or PowerPoint."

One perspective advocates the benefits of "failing fast" in order to appreciate emerging possibilities through prototyping (described in Thomke, 2003). An enactment perspective to which we subscribe provides a slightly different orientation. It is not "fail fast" but rather "experiment fast." That is, prototyping is a process by which actors probe and create a world that is both possible and desirable (Boland and Collopy, 2004; Hatchuel 2002), with each prototype serving as an intermediate step that adds to an emerging platform of options (Ciborra, 1996). This was the case in Gmail, as illustrated in the pre-release screenshots, where each prototype acted as an intermediate step to cumulatively add and iteratively refine the functionalities toward the development of the product.

Collective engagement. As described in the Project Caribou case, collective engagement occurs in public forums (physical and virtual) that offer employees an opportunity to demonstrate their prototypes to other employees at Google. Publicly demonstrating the outcomes of initiatives serves to build and signal commitment, an important part of a company's action 
orientation (Brunsson, 1982). In addition, demonstration helps enroll the support of actors from all across the company. Once convinced, these actors will have their own insights on the innovation in-the-making.

Besides generating feedback from multiple actors, collective engagement in public forums also serves as a venue for facilitating the recombination of ideas (Hargadon, 2003). For instance, the AJAX grouplet served as a key mechanism for the adoption of JavaScript and XHR in building web applications. It is through this technique that Google was able to develop an organizational capability to build RIAs (Rich Internet Applications).

Interactions that unfold between prototype developers and users are particularly worth noting. Normally, producers are driven by intuition and are enabled and constrained by the resources available to them. On the other side, functionality is often discovered in use. These two processes converged at Google. In the case of Gmail, developers acted as users by trying out the email prototype during their day-to-day activities. Similarly, other users of the prototype had the option of either filing a bug report or fixing the bugs they found (“...he told me to fix [the bug] myself, pointing me to a document on how to bring up the Gmail development environment on my workstation.").

This dynamic between 'developers as users' and 'users as developers' generated a momentum that was needed for sustaining collective engagement. In addition, it led to a reconsideration by management of their beliefs about the technology at work and the business models in use, which were shaped by the organization's identity around search (Mayer even noted her reservations, "...two of the other people who are using the email are Larry and Sergey. And Larry and Sergey, they have weird views of these ads and privacy"). 
Appreciating the benefits of connecting production with use, Google has created Gmail Labs, where it lists experimental features available to the public (see Thomke, 2003 for shifting the locus of innovation to end users). By trying out new features, users signal which ones they consider most useful. These features are then integrated into the design of the core product.

\section{Interactions between Mechanisms}

Although interconnected, each mechanism can operate on its own. For instance, a firm can encourage reflection-through-action without institutionalizing prototyping capabilities. Even if a firm institutionalizes prototyping, public forums for collective engagement may not exist. However, the value of each mechanism is amplified when operating with the others, which was the case at Google. We discuss these interactions by focusing on the edges in the model in Figure 1. These are labeled as concretization of ideas (Link 1), establishing legitimacy (Link 2), and collective reflection (Link 3) respectively. We discuss these in greater detail below.

-- Insert Figure 1 Here --

Concretization of ideas (Link 1). The first link we discuss is between reflectionthrough-action and prototyping. This link alludes to the materialization of ideas through reflective actions, and represents an iterative unfolding of nebulous ideas into practice (Sennett, 2008). Each prototype serves as an intermediate step that demonstrates "the feasibility of the principle, and of the methods which make it feasible" (Dewey, 1956: 93-94).

For instance, at Google, Buchheit did not have a 'fully-formed' idea about the features of the new email to address his colleague's comment on spending all her time finding and filing messages or deleting them to stay under the obligatory four megabyte limit. Schön (1983: 79) noted that practitioners respond to such ambiguities "by forming new appreciations and understandings, and by making new moves. He shapes the situation in accordance with his initial 
appreciation of it, the situation 'talks back' and he responds to the situation's back-talk." Herbert Simon (1996) describes this process involving "talk-back" and "back-talk" with an analogy:

In oil painting, every new spot of pigment laid on the canvas creates some kind of pattern that provides a continuing source of new ideas to the painter. The painting process is a process of cyclical interaction between the painter and canvas in which current goals lead to new applications of paint, while the gradually changing pattern suggests new goals. (Simon, 1996)

Analogous dynamics were evident during the emergence of Gmail. While prototyping, Buchheit found latency in response times that existing programming tools and techniques generated. Unlike web search, latency is a problem for an email application, as there cannot be any time lag between the sending and receiving of emails. Encountering this "talk-back," Buchheit started exploring the use of JavaScript. Such "resistances and accommodations" (Pickering, 1993) through prototyping and reflection-through-action allowed for the iterative materialization of a nascent idea.

Establishing legitimacy (Link 2). Crude prototypes, while useful for establishing proofof-concept, may appear as hopeful monstrosities to others (Goldschmidt, 1940; Mokyr, 1990). Especially with identity-challenging prototypes, there may be illegitimacy attached (Dougherty and Heller, 1994), as was the case with Gmail, JavaScript, and AdSense. As a result, hopeful monstrosities are unable to attract organizational resources to develop and grow. How might organizations overcome this liability of emergence?

This is where establishing legitimacy is important. Rather than protect such innovations within hidden spaces such as skunk-works (Rich and Janos, 1994), Gmail and AdSense were showcased across institutionalized public spaces at Google. These physical (e.g., demo slams) and virtual (e.g., LAN, intranet) forums served as "liminal spaces...that liberate participants from routine activity" (Turner, 1986), and act as "occasions for the legitimate performance of 
illicit behavior" (Rao and Dutta, 2012). Stated in another way, these spaces offered employees the micro-institutional affordances for multiple employees with heterogeneous perspectives to interact with one another for dealing with ambiguous phenomena (van Dijk et al., 2011).

At these forums, actors demonstrate their prototypes in a way that calls for engagement (e.g., live code) thereby translating it for others. The required language to describe these artifacts may not exist, as the ideas are still nascent. From an emergence perspective, inability to label a prototype may be beneficial, as the lack of a label may allow others to ascribe functionality based on what they can see, hear, and touch. For instance, Mayer's preferences emerged through use when she experienced content-targeted ads, which were shared across the company's LAN. A challenge to collective engagement arises when actors hail from different thought worlds (Dougherty, 1992; Dunne and Dougherty, 2016). Alleviating this problem is the possibility of prototypes serving as "boundary objects" (Star and Griesemer, 1989), which are coherent yet plastic at the same time, allowing for different social groups an opportunity to interact. Prototypes that were demonstrated and circulated across the company's LAN served as boundary objects. It is through such interactions that user preferences, organizational capabilities, and meanings emerged at Google. Prototypes were not just models of ideas in the minds of some actors. Instead, they served as models for the development of new possibilities that emerge through actions and interactions ("What I wrote was just a throwaway prototype, but it got people thinking because it proved that it was possible, and that it wasn't too hard because I was able to do it in less than a day. After that, other people took over and did all the hard work of making it into a real product.")

Collective reflection (Link 3). We have already alluded to the instantiation of ideas as prototypes that emerge (Link 1), and their legitimization through demonstrations in public spaces 
(Link 2). Link 3 represents collective reflection on the utility of the emergent innovation. While building on the remaining two links, collective reflection has a distinctive role in the reconsideration of deeply held values and beliefs about phenomena by actors.

How does collective reflection lead to such reconsideration? Actors do not want to publicly take a contrarian position that might challenge the identity of an organization, especially when they are uncertain about how others will react. Explaining the pluralistic challenge that can emerge, Chwe (2001, p.10-12) noted:

...each individual wants to participate only if others do, each person must also know that others received a message. For that matter, because each person knows that other people need to be confident that others will participate, each person must know that other people know that other people have received a message, and so forth.

It is here that demonstrations of projects in public forums can help. These demonstrations result in the generation of "common knowledge" (i.e., everyone knowing that everyone knows) about ideas and prototypes, thereby breaking pluralistic silence. When the working model of Gmail was publicly demonstrated at demo slams and across the company's LAN, a growing number of Google employees started seeing the benefit of not just the Gmail application, but also the underlying JavaScript technology. This, in turn, led to the creation of grouplets for learning and improving the technology, which then evolved to become AJAX. As ideas about "what can be" rather than "what is" (Goodman, 1978; Simon, 1996) were realized, even the skeptics at Google decided to reconsider their beliefs about the technologies at work and the business models in use.

Such reconsideration speaks to the evaluative dimension of reflection in practice (Yanow and Tsoukas, 2009). This evaluative dimension, based on pragmatic philosophy (Dewey, 1956), offers a different pathway to gaining legitimacy for products and practices than the ones 
identified by Dougherty and Heller (1994), viz. conformance, ceremonial acceptance, or reframing (by using legitimate practices as analogies). Instead of conforming to the existing technologies at work and business models in use, employees at Google deviated from them (e.g., JavaScript). Similarly, rather than use existing technologies and business models, actors experimented with new ones (e.g., Adsense).

These examples offer a way for actors to reconsider their deeply held beliefs and values about technologies at work and business models in use. A "careful consideration of beliefs in light of supporting evidence" is involved (King and Kitchener 2004:6) (quoted in Yanow and Tsoukas, 2009). Such reconsideration is based not just on establishing cognitive or pragmatic legitimacy (Suchman, 1995) as highlighted earlier in Link 2, but in addition, a deeper secondorder reexamination of underlying values and beliefs.

\section{Process-based Organizational Ideology of Participative Experimentation}

Together, the three mechanisms constitute an organizational ideology of participative experimentation. Based on work by Rescher (1996), we note that this process-based ideology lies in contrast to a substance-based ideology wherein actors have fixed identities and technologies have known functionalities. In particular, a process-based ideology considers actors' identities and technological functionalities as emergent. Rescher (1996: 27) highlighted "process philosophy does not—or need not—deny substances (things), but sees them as subordinate in status and ultimately inhering in processes." 11

Google valued a process-based ideology of participatory experimentation over a substance-based ideology as is evident in the dynamics associated with the emergence of Gmail

${ }^{11}$ To draw an analogy from the political realm, a process-based ideology of participation is akin to placing greater value on processual facets of a democracy (e.g., elections, townhall meetings, presidential debates) than on the particular positions of the different members of the electorate on substantive issues (e.g., climate, guns, stem-cells). 
and AdSense. The first Gmail prototype emerged from low-cost experimentation carried out with the existing Google Groups codebase. When circulated through the internal corporate LAN and showcased at demo slams, the prototype made the case for building an email application and for using JavaScript. Before Gmail, JavaScript was not acceptable at Google. It was associated with pop-up ads and pornography, which conflicted with the value that the company placed on the primacy of user experience. Yet, Google employees decided to use JavaScript, as this was essential for the innovations that emerged.

Participative experimentation also led to AdSense, which was developed by combining existing code bases. Not only did Google realize the value of context-sensitive ads (which it had eschewed before), it also realized that these ads could be displayed within various other web pages and applications, including the Google "search results" page. Similarly, the outcomes of multiple reflective activities were combined into collaborative grouplets, which enabled the diffusion of the AJAX programming technique both within and outside the organization.

It is instructive to compare the dynamics that unfolded at Google with those at Intel when the latter shifted from DRAMs to microprocessors. As described by Burgelman (1983), Intel's top management team focused their attention on selling DRAMs, around which the company had forged a recognizable identity. Unbeknownst to top management, however, Intel employees began selling microprocessors. The availability of this option made it possible for the company to shift to microprocessors when the DRAM market collapsed because of competition. Overall, the availability of an alternative was because of the microprocessor initiative slipping through Intel's selection environment that is shaped by top-management.

The dynamics that unfolded in the emergence of Gmail and Adsense at Google confirm the importance of bottom up autonomous processes for the survival and growth of firms. 
However, there is a difference between the two cases. In Intel's case, the microprocessor alternative was able to emerge because it slipped through the company's selection environment. By contrast, the Google case shows how a company can proactively engage in practices that generate identity-challenging innovations through a process-based ideology of participative experimentation.

Participative experimentation is not unique to Google. $3 \mathrm{M}$ Corporation too gives primacy to participative experimentation over a fixed organizational identity based on any one of its products (Garud, Gehman and Kumaraswamy, 2011). When asked about the importance of innovation, 3M's senior vice president of R\&D said: “We don't know what business we will be in 50 years from now. But it is because we don't know that we will still be in business." (Interview conducted by one of the authors). Indeed, innovation has always been a part of the company's identity as evidenced by 3M's logo '3M INNOVATION', which it embraced for a period of time.

\section{DISCUSSION AND CONCLUSION}

We began the paper by inquiring into the possibility of addressing the challenges that firms confront in nurturing identity-challenging innovations. We found that an organizational ideology of participative experimentation made it possible for employees at Google to nurture innovations that challenged the company's identity. Constituting participative experimentation are three mechanisms, viz., reflection-through-action, prototyping, and collective engagement. Reflection-through-action locates innovation rights at the scene of action, thereby distributing it across employees. Prototyping makes it possible for actors to demonstrate proof of concept for novel ideas even when these ideas are difficult to describe. Collective engagement facilitates the scaling-up of promising ideas by bringing together distributed efforts. 
We revisit Figure 1 to summarize an overall model detailing how a process-based ideology of participative experimentation can generate identity-challenging innovations. At any point in time, organizations may have an identity based on employees' collective understanding of 'who we are', which connects with 'what we do' (see also Ravasi, Tripsas, and Langley, 2017). A commitment to 'what we do' arises from a shared organizational ideology around substances and processes. Organizations that predominantly value a substance-based ideology (wherein the identities of people and the functionalities of technologies are given and fixed) might favor identity-enhancing over identity-challenging innovations.

As identity-challenging innovations are essential for survival and growth in environments characterized by discontinuous change, organizations might consider embracing a process-based ideology of participative experimentation. With such an ideology, legitimacy is gained not through conformance, reframing, and ceremonial practices (Dougherty and Heller, 1994), as is the case with a substance-based ideology, but through a second-order examination of the deeply held beliefs in light of supporting evidence (King and Kitchener 2004). Even identitychallenging innovations that emerge from such a participative process will be resourced to the extent they have any merit. Over time, the identity-challenging innovations that are successful can reconfigure the organization's identity.

The data allowed us to talk about the dynamics that unfolded across the two innovations we studied. As such, we found that the process-based organizational ideology of participative experimentation was valued more than the substance-based ideology encompassing the technologies in use. The availability of more fine-grained data on each innovation would have made it possible to provide greater specificity to the relationships between process-based and 
substance-based ideologies. Future research in other settings can further explore the links between the two.

For instance, we would expect to find dynamics similar to those at Google in firms involved with digital innovations (Nambisan et al, 2016; Yoo, Boland, Lyytinen and Majchrzak, 2012) where the costs associated with experimentation and interaction have dropped significantly (Schrage, 2000; Thomke, 2003). These firms employ a variety of methods and tools such as wireframing, concept mapping, scenario building, and story-boarding within collective spaces such as studios and idea-labs. These new practices are part of a "hacking culture" that firms are using to spur innovations (Coleman, 2013).

However, industries where discontinuous innovations require non-trivial upfront investments may exhibit dynamics that are different from the ones we found at Google. As an example, Lynn et al. (1996) found that it took considerable time, resources, and effort for GE, Motorola, Corning, and Searle to "probe and learn" about the discontinuous innovations the companies were introducing into new markets. Organizations operating in high-reliability environments (Weick, Sutcliffe, and Obsfeld, 2008), such as nuclear energy where the impact of negative outcomes could be catastrophic, are also likely to exhibit a different set of dynamics. Such organizations may have to resort to 'experimentation with simulations,' a practice that is being embraced by oil and energy companies (Parmiggiani, Monteiro, and Østerlie, 2016).

The fact that Google is a for-profit company is yet another factor that must be considered when transferring insights from this study to other settings. There are pluralistic organizations such as hospitals and schools comprised of multiple stakeholders with different needs (Denis, Langley, and Rouleau, 2007). Such organizations are more likely to experience "networks of indecisions" (Denis et al., 2011), especially when they confront the need for fundamental 
change. In such situations, how might a process-based ideology of participation experimentation help engender change? What else is required to ensure transformation rather than indecision? Future research can shed further light on these and other related questions. 


\section{REFERENCES}

Anthony C and Tripsas M (2016) Organizational identity and innovation. In: Pratt MG, Schultz M, Ashforth BE and Ravasi D (eds). The Oxford Handbook of Organizational Identity. New York, NY, pp.21-39.

Battelle J (2005) The Search: How Google and its rivals rewrote the rules of business and transformed our culture. Portfolio Hardcover, New York, NY.

BBC (2004). Timing makes Google an April fool. (http://news.bbc.co.uk/2/hi/business/3591589.stm). [Accessed on November 8, 2009.]

Bartel, C. and Garud, R. (2009) "The role of narratives in sustaining organizational innovation Organization Science. Vol. 20, No. 1, pp. 107-117.

Berkun S (2008). Thoughts on Google's 20\% Time. http://www.scottberkun.com/blog/2008/thoughts-on-googles-20-time/ [Accessed on October 10, 2009]

Beyer JM and Trice HM (1981) Managerial ideologies and the use of discipline. Academy of Management Proceedings, pp. 259-263.

Beyer JM, Dunbar RL and Meyer AD (1988) Comment: The concept of ideology in organizational analysis. Academy of Management Review 13(3): 483-489.

Boland RJ and Collopy F (2004) Design matters for management. In Boland, R.J., Collopy, F., (Eds.), Managing as designing. Stanford University Press, Stanford, CA, pp. 3-18.

Bouchikhi H and Kimberly JR (2003) Escaping the identity trap. MIT Sloan Management Review 44(3): 20-24.

Brin S and Page L (1998). The anatomy of a large-scale hypertextual Web search engine. Computer Networks and ISDN Systems 30, 107-117.

Brown JS (1997) Seeing differently: Insights on innovation. Harvard Business Press. Cambridge, MA.

Brunsson N (1976) Propensity to change. : B.A.S. Goteborg, Sweden.

Brunsson N (1982) The irrationality of action and action rationality: decisions, ideologies and organizational actions. Journal of Management Studies 19(1): 29-44.

Burgelman RA (1983) A process model of internal corporate venturing in the diversified major firm. Administrative Science Quarterly 28(2): 223-244.

Burgelman RA (2011) Bridging history and reductionism: A key role for longitudinal qualitative research. Journal of International Business Studies 42(5): 591-601.

Buchheit P (2005). Guess what just turned 34? (http://googleblog.blogspot.com/2005/10/guesswhat-just-turned-34.html). [Accessed on January 10, 2010]

Buchheit P (2009a). Communicating with code. (http://paulbuchheit.blogspot.com/2009/01/communicating-with-code.html). [Accessed on January 10, 2010]

Buchheit P (2009b). Overnight Success takes a long time. (http://paulbuchheit.blogspot.com/2009/01/overnight-success-takes-long-time.html). [Accessed on January 10, 2010]

Businessweek (2010). The 50 Most Innovative Companies 2010. Bloomberg Businessweek online.

(http://www.businessweek.com/interactive reports/innovative_companies_2010.html).

[Accessed on January 23, 2011]

Charmaz K (2006) Constructing grounded theory: A practical guide through qualitative analysis. 
Sage Publications, Thousand Oaks, CA.

Chwe MS-Y (2001) Rational ritual: Culture, coordination, and common knowledge. Princeton University Press, NJ.

Ciborra CU (1996) The platform organization: Recombining strategies, structures, and surprises. Organization Science 7(2): 103-118.

Coleman EG (2013) Coding freedom: The ethics and aesthetics of hacking. Princeton University Press, NJ.

Coleman, K., (2008). Introducing Gmail Labs. (http://gmailblog.blogspot.com/2008/06/introducing-gmail-labs.html). [Accessed on March 15, 2010]

Cooper RG (1990) Stage-gate systems: A new tool for managing new products. Business Horizons 33(3): 44-54.

Daft RL and Lengel RH (1986). Organizational information requirements, media richness and structural design. Management Science, 32(5): 554-571.

Danneels E (2011) Trying to become a different type of company: dynamic capability at Smith Corona. Strategic Management Journal 32(1): 1-31.

Denis J-L, Langley A and Rouleau L (2007) Strategizing in pluralistic contexts: Rethinking theoretical frames. Human Relations 60(1): 179-215.

Denis J-L, Dompierre G, Langley A, et al. (2011) Escalating Indecision: Between Reification and Strategic Ambiguity. Organization Science 22(1): 225-244.

Dewey J (1956) The school and society and the child and the curriculum. University of Chicago Press, Chicago, IL.

Dougherty D (1992) Interpretive barriers to successful product innovation in large firms. Organization Science 3(2): 179-202.

Dunne DD and Dougherty D (2016). Abductive Reasoning: How Innovators Navigate in the Labyrinth of Complex Product Innovation. Organization Studies 37(2), 131-159.

Dougherty D and Heller T (1994) The illegitimacy of successful product innovation in established firms. Organization Science 5(2): 200-218.

Dunbar RL and Garud R (2009) Distributed knowledge and indeterminate meaning: The case of the Columbia shuttle flight. Organization Studies 30(4): 397-421.

Edelman, B.G., Eisenmann, T.R., (2010). 'Google Inc.' Harvard Business School Cases \#910036.

Fast Company (2010). The World's Most Innovative Companies. (http://www.fastcompany.com/mic/2010). [Accessed on January 12, 2011]

Fine GA and Sandstrom K (1993) Ideology in action: A pragmatic approach to a contested concept. Sociological Theory, 11(1): 21-38.

Fiol CM (2002) Capitalizing on paradox: The role of language in transforming organizational identities. Organization Science 13(6): 653-666.

Garud R, Gehman J and Kumaraswamy A (2011) Complexity arrangements for sustained innovation: Lessons from 3M Corporation. Organization Studies 32(6), 737-767.

Garud R and Rappa M (1994) A socio-cognitive model of technology evolution Organization Science, Vol. 5, No. 3, pp. 344-362.

Garud R and Van de Ven AH (1992) An empirical evaluation of the internal corporate venturing process" Strategic Management Journal, Vol. 13, 93-109.

Gioia DA and Hamilton AL (2016) Great Debates in Organizational Identity Study. The Oxford Handbook of Organizational Identity In: Pratt MG, Schultz M, Ashforth BE and Ravasi 
D (eds). The Oxford Handbook of Organizational Identity. New York, NY, pp.21-39.

Gioia DA, Patvardhan SD, Hamilton AL, and Corley KG (2013) Organizational identity

formation and change. Academy of Management Annals, 7(1), 123-193.

Girard B (2009) The Google way: How one company is revolutionizing management as we know it. No Starch Press, San Francisco, CA.

Glaser BG (1965) The constant comparative method of qualitative analysis. Social Problems, 12(4), 436-445.

Glynn MA (2000) When cymbals become symbols: Conflict over organizational identity within a symphony orchestra. Organization Science 11(3): 285-298.

Goldschmidt R (1940) The material basis of evolution. Yale University Press.

Goodman N (1978) Ways of worldmaking. Hackett Publishing, Indianapolis, IN.

Google (2004a). Google Copernicus Center is Hiring.

(http://www.google.com/jobs/lunar_job.html) [Accessed on October 5, 2009].

Google (2004b). Search is Number Two Online Activity - Email is Number One; 'Heck, Yeah,' Say Google Founders . (http://www.google.com/press/pressrel/gmail.html). [Accessed on October 09, 2009]

Google (2010). Google Corporate Information.

(http://www.google.com/about/corporate/company). [Accessed on December 14, 2010]

Groysberg B, Thomas DA and Wagonfeld AB (2009). Keeping Google 'Googley'. \#409039PDF-ENG

Hamel G and Breen B (2007). The Future of Management. Harvard Business School Press. Cambridge, MA.

Hargadon AB (2002) Brokering knowledge: Linking learning and innovation. Research in Organizational behavior 24: 41-85.

Hargadon A (2003). How breakthroughs happen: The surprising truth about how companies innovate. Harvard Business Press, Cambridge, MA.

Hargadon AB and Douglas Y (2001). When innovations meet institutions: Edison and the design of the electric light. Administrative Science Quarterly, 46(3), 476-501.

Hatch MJ, Schultz M and Skov AM (2015). Organizational identity and culture in the context of managed change: Transformation in the Carlsberg Group, 2009-2013. Academy of Management Discoveries, 1(1), 56-87.

Hatchuel A (2002). Towards design theory and expandable rationality: The unfinished program of Herbert Simon. Journal of Management and Governance 5(1), 260-273.

Hendrickson M (2008). The Evolution of PreLaunch Gmail in Screenshots. (http://techcrunch.com/2008/06/06/the-evolution-of-pre-launch-gmail-inscreenshots).[Accessed on May 18, 2009]

Hernes T and Schultz M (2017). A Temporal Understanding of the Connections between Organizational Culture and Identity. In: Langley, A and Tsoukas H (eds). The SAGE Handbook of Process Organization Studies, pp.356-371.

Hild M and Mitchell J (2004). Free Email: Google, MSN Hotmail and Yahoo! (A). Darden Business Cases \#UVA-QA-0642.

Iinovate (2007). Marissa Mayer, VP of Search Products and User Experience at Google Interview Podcast. (http://iinnovate.blogspot.com/2007/08/marissa-mayer-vp-of-searchproducts-and.html). [Accessed on March 18, 2009]

Iyer B and Davenport TH (2008) Reverse Engineering: Google's Innovation Machine. Harvard Business Review 86(4). 
Jick TD (1979) Mixing qualitative and quantitative methods: Triangulation in action. Administrative Science Quarterly 24(4): 602-611.

Joseph J and Ocasio W (2012) Architecture, attention, and adaptation in the multibusiness firm: General electric from 1951 to 2001. Strategic Management Journal 33(6): 633-660.

Kahl SJ, Silverman BS, Cusumano MA, et al. (2012) The integration of history and strategy research. History and Strategy, Advances in Strategic Management.

Kalyn W (2009). Designing Woman : Marissa Mayer, VP of Search Products and User Experience. (http://www.wetfeet.com/MBA/Entrepreneurship/Articles/DesigningWomen.aspx). [Accessed on March 12, 2010]

King PM and Kitchener KS (2004) Reflective judgment: Theory and research on the development of epistemic assumptions through adulthood. Educational psychologist 39(1): 5-18.

Langley A (1999) Strategies for theorizing from process data. Academy of Management Review 24(4): 691-710.

Langley A, Smallman, C, Tsoukas H et al., (2013). Process studies of change in organization and management: unveiling temporality, activity, and flow. Academy of Management Journal 56(1): 1-13.

Levy S (2011) In the Plex: How Google thinks, works, and shapes our lives. Simon and Schuster, New York, NY.

Lucas HC and Goh JM (2009) Disruptive technology: How Kodak missed the digital photography revolution. The Journal of Strategic Information Systems 18(1): 46-55.

Levi-Strauss C (1966). The Savage Mind. University of Chicago Press, Chicago, IL.

Lincoln YS and Guba EG (1986) But is it rigorous? Trustworthiness and authenticity in naturalistic evaluation. New directions for program evaluation 1986(30): 73-84.

Livingston J (2007). Founders at Work: Stories of Startups' Early Days. Apress, New York City, NY.

Lynn GS, Morone JG and Paulson AS (1996) Marketing and Discontinuous Innovation: The Probe and Learn Process. California Management Review 38(3): 8.

Mangalindan M and Buckman R (2005). New Web-based Technology Draws Applications, Investors. (http://online.wsj.com/public/article/SB1130986355874870743diFzslPm_iutdYLU2C5e4DinUA_20061103.html). [Accessed on October 10, 2009]

Mediratta B (2007). The Google Way: Give Engineers Room. (http://www.nytimes.com/2007/10/21/jobs/21pre.html) [Accessed on October 26, 2009]

Meyer AD (1982) How ideologies supplant formal structures and shape responses to environments. Journal of Management Studies 19(1): 45-61.

Meyer AD (1991) Visual data in organizational research. Organization Science 2(2): 218-236.

Miles MB and Huberman AM (1994) Qualitative data analysis: An expanded sourcebook. Sage. Moon YE, Chen D (2007). Google Advertising. Harvard Business School Case \#507-038.

Mokyr J (1990) Punctuated equilibria and technological progress. American Economic Review 80(2): 350-354.

Murmann JP (2012) Marrying history and social science in strategy research. Advances in Strategic Management 29: 89-115.

Nag R, Corley KG and Gioia DA (2007) The intersection of organizational identity, knowledge, and practice: Attempting strategic change via knowledge grafting. Academy of Management Journal 50(4): 821-847.

Nambisan S, Lyytinen K, Majchrzak A and Song M (2016). Digital Innovation Management: 
Reinventing Innovation Management Research in a Digital World. MIS Quarterly, 41(1), 223-238.

Nuttall, C., (2009). Google in push to gain e-mail market share. (http://www.ft.com/cms/s/0/18cdabec-d8fb-11dd-ab5f000077b07658.html\#axzz1AFAf7xxb). [Accessed on November 09, 2010]

Page L (2004). Inside the Google Machine. TED Conference, Monterey, CA.

Parmiggiani E, Monteiro E and Østerlie T (2016) Synthetic Situations in the Internet of Things. In: Introna L, Kavanagh D, Kelly S, et al. (eds), Beyond Interpretivism? New Encounters with Technology and Organization: IFIP WG 8.2 Working Conference on Information Systems and Organizations, Springer International Publishing, pp. 215-228. Available from: http://dx.doi.org/10.1007/978-3-319-49733-4_13.

Pickering A (1993). The mangle of practice: Agency and emergence in the sociology of science. American Journal of Sociology 99(3): 559-589.

Rao H and Dutta S (2012) Free spaces as organizational weapons of the weak religious festivals and regimental mutinies in the 1857 Bengal native army. Administrative Science Quarterly 57(4): 625-668.

Ravasi D and Phillips N (2011) Strategies of alignment organizational identity management and strategic change at Bang \& Olufsen. Strategic Organization 9(2): 103-135.

Ravasi D and Schultz M (2006) Responding to organizational identity threats: Exploring the role of organizational culture. Academy of management journal 49(3): 433-458.

Ravasi D, Tripsas M and Langley A (2017) Call for Papers: Special Issue of Strategic Organization "Exploring the Strategy-Identity Nexus." Strategic Organization.

Rescher N (1996) Process metaphysics: An introduction to process philosophy. SUNY Press, NY.

Rich, B.R., Janos, L. (1994). Skunk works: A personal memoir of my years at Lockheed. Little, Brown Co, Boston, MA.

Rindova VP, Yeow A, Martins LL et al. (2012). Partnering portfolios, value-creation logics, and growth trajectories: A comparison of Yahoo and Google (1995 to 2007). Strategic Entrepreneurship Journal 6, 133-151.

Schön DA (1983) The reflective practitioner: How professionals think in action. Basic books, New York, NY.

Schrage M (2000) Serious play: How the world's best companies simulate to innovate. Harvard Business Press, Cambridge, MA.

Schultz M and Hernes T (2013) A temporal perspective on organizational identity. Organization Science 24(1): 1-21.

Schmidt E and Rosenberg J (2014). How Google works. Hachette, London, United Kingdom. Siggelkow N (2002) Evolution toward fit. Administrative Science Quarterly 47(1): 125-159. Simon H (1996). The Sciences of the Artificial (3rd Edition). The MIT Press, Cambridge, MA. Slashdot (2004). Google's Gmail To Offer 1GB E-mail Storage?

(http://slashdot.org/article.pl?sid=04/04/01/0038200andmode=threadandtid=126andtid=9

5) [Accessed on November 08, 2009]

Star SL and Griesemer JR (1989) Institutional ecology, translations' and boundary objects:

Amateurs and professionals in Berkeley's Museum of Vertebrate Zoology, 1907-39.

Social Studies of Science 19(3): 387-420.

Sennett R (2008) The craftsman. Yale University Press, Hartford, Connecticut.

Starbuck WH (1982) Congealing oil: Inventing ideologies to justify acting ideologies out. 
Journal of Management Studies 19(1): 3-27.

Starbuck WH (1983) Organizations as action generators. American Sociological Review: 91-102.

Strauss A and Corbin J (1998) Basics of qualitative research: Techniques and procedures for developing grounded theory. Sage, Thousand Oaks, CA.

Suchman MC (1995) Managing legitimacy: Strategic and institutional approaches. Academy of Management Review 20(3): 571-610.

Stross R (2008). Planet Google: One company's audacious plan to organize everything we know. Free Press, Glencoe, IL.

Sullivan D (1999). Google goes forward. (http://searchenginewatch.com/2167311). [Accessed on November 06, 2009]

Sullivan D (2004). Google launches Gmail, free email service. (http://searchenginewatch.com/3334241). [Accessed on November 06, 2009]

Temkin D (2005). New web-based technology draws applications, investors. (http://online.wsj.com/public/article/SB1130986355874870743diFzslPm_iutdYLU2C5e4DinUA_20061103.html). [Accessed on October 18, 2009]

Thomke SH (2003) Experimentation matters: unlocking the potential of new technologies for innovation. Harvard Business Press.

Tripsas M (2009) Technology, identity, and inertia through the lens of 'The Digital Photography Company'. Organization Science 20(2): 441-460.

Tripsas M and Gavetti G (2000) Capabilities, cognition, and inertia: Evidence from digital imaging. Strategic Management Journal 21(10-11): 1147-1161.

Tsoukas H (2009) Craving for generality and small-N studies: A Wittgensteinian approach towards the epistemology of the particular in organization and management studies.

Tsoukas H and Hatch MJ (2001) Complex thinking, complex practice: The case for a narrative approach to organizational complexity. Human Relations 54(8): 979-1013.

Turner VW (1986) Dewey, Dilthey, and drama: An essay in the anthropology of experience. In: Turner, VW and Bruner, EM (eds.), The Anthropology of Experience: 33-44. University of Illinois Press, Champaign, IL.

Tuertscher P, Garud R and Kumaraswamy A (2014) Justification and interlaced knowledge at ATLAS, CERN. Organization Science, 25:1579-1608.

Van de Ven AH and Poole MS (1990) Methods for studying innovation development in the Minnesota Innovation Research Program. Organization Science 1(3): 313-335.

Van de Ven AH and Poole MS (2005) Alternative approaches for studying organizational change. Organization Studies 26(9): 1377-1404.

Van Dijk S, Berends H, Jelinek M, et al. (2011) Micro-institutional affordances and strategies of radical innovation. Organization Studies 32(11): 1485-1513.

Vise DA and Malseed M (2007) The Google Story: For Google's 10th Birthday. Bantam Dell, New York.

Vuori TO and Huy QN (2016) Distributed Attention and Shared Emotions in the Innovation Process How Nokia Lost the Smartphone Battle. Administrative Science Quarterly: 1839215606951.

Weick KE (1995) Sensemaking in organizations Sage Publications, Thousand Oaks, CA.

Weick KE, Sutcliffe KS and Obstfeld D (2008) Organizing for high reliability: Processes of collective mindfulness Crisis management 3.1: 81-123.

Yanow D and Tsoukas H (2009) What is reflection- in- action? A phenomenological account. Journal of Management Studies 46(8): 1339-1364. 
Yegge S (2006). Good agile, bad agile.(http://steve-yegge.blogspot.com/2006/09/good-agilebad-agile 27.html). [Accessed on November 10, 2009]

Yoo Y, Boland Jr RJ, Lyytinen K, et al. (2012) Organizing for innovation in the digitized world. Organization Science 23(5): 1398-1408.

Zammuto RF, Gifford B, and Goodman EA (2000) Managerial ideologies, organization culture and the outcomes of innovation: A competing values perspective. 
TABLE 1: DATA SOURCES

\begin{tabular}{|c|c|c|}
\hline Type & Number & Description \\
\hline \multicolumn{2}{|l|}{ Project } & \\
\hline $\begin{array}{l}\text { Audio Interviews and Video Talks } \\
\text { (given to third-parties) }\end{array}$ & 7 & \multirow{6}{*}{$\begin{array}{l}\text { Data collected at the project level focused on the dynamics that } \\
\text { ensued within Project Caribou, and its outcomes. Audio } \\
\text { interviews and video talks of actors involved in the project } \\
\text { provided us with an understanding of the events that } \\
\text { transpired. Personal blogposts by Paul Buchheit provided a } \\
\text { more contextualized account of the processes that unfolded. } \\
\text { Official blogposts and product pre-launch screenshots helped } \\
\text { us generate the trajectory of the project and its outcomes. }\end{array}$} \\
\hline Personal Blogposts & 12 & \\
\hline Official Blogposts & 6 & \\
\hline Product Pre-Launch Screenshots & 14 & \\
\hline Product Videos & 8 & \\
\hline Business Press Articles & 23 & \\
\hline \multicolumn{2}{|l|}{ Organization } & \\
\hline Books written about Google & 6 & \multirow{9}{*}{$\begin{array}{l}\text { Data gathered at the organizational level focused on the } \\
\text { internal work culture, practices, and technologies used within } \\
\text { Google. This includes details around how work is structured } \\
\text { within Google, how new ideas are vetted, and how nascent } \\
\text { initiatives gets expanded across the organization. This data } \\
\text { helped us identify the mechanisms that enabled the company } \\
\text { to establish a supportive organizational context for ongoing } \\
\text { innovation. }\end{array}$} \\
\hline Academic Case Studies & 9 & \\
\hline $\begin{array}{l}\text { Business Press Articles (from } \\
\text { multiple databases) }\end{array}$ & 115 & \\
\hline Official Blogposts & 92 & \\
\hline $\begin{array}{l}\text { Personal Blogposts of Current and } \\
\text { Ex-Google Employees }\end{array}$ & 65 & \\
\hline Video Documentaries on Google & 8 & \\
\hline Annual Reports & 8 & \\
\hline $\begin{array}{l}\text { Technical Reports and Papers } \\
\text { published by Google }\end{array}$ & 27 & \\
\hline Analyst Reports & 45 & \\
\hline \multicolumn{2}{|l|}{ Industry } & \\
\hline Books & 3 & \multirow{6}{*}{$\begin{array}{l}\text { Data collected at the industry level helped us unpack the } \\
\text { evolution of the "web" technological field following the dot- } \\
\text { com crash when Project Caribou took shape. This data also } \\
\text { helped us understand the shared beliefs held by technology } \\
\text { analysts and experts on web-based programing tools and } \\
\text { frameworks pre- and post- the dot-com crash. }\end{array}$} \\
\hline $\begin{array}{l}\text { Analyst Reports (from multiple } \\
\text { databases) }\end{array}$ & 40 & \\
\hline Business Press Articles & 65 & \\
\hline $\begin{array}{l}\text { E-Business trends and forecasting } \\
\text { reports } \\
\text { (pre- and post- the dot com crash) }\end{array}$ & 28 & \\
\hline $\begin{array}{l}\text { Web-based technologies: trends and } \\
\text { forecasting reports (pre- and post- } \\
\text { the dot com crash) }\end{array}$ & 15 & \\
\hline Total & $\sim 600$ & \\
\hline
\end{tabular}




\section{TABLE 2: ABBREVIATED CHRONOLOGY OF EVENTS AT GOOGLE}

\begin{tabular}{|c|c|}
\hline Year & Description \\
\hline Mar 1996 & $\begin{array}{l}\text { Larry Page and Sergey Brin start working on the Stanford Digital Library Project (SDLP). They begin } \\
\text { collaborating on a search engine called 'BackRub'. }\end{array}$ \\
\hline Sep 1997 & $\begin{array}{l}\text { Page and Brin decide to take Backrub online. They name it 'Google' and the domain name 'google.com' } \\
\text { goes online. }\end{array}$ \\
\hline Aug 1998 & $\begin{array}{l}\text { Google gets its first funding -- a contribution of US\$100,000 - from Andy Bechtolsheim, the co-founder of } \\
\text { Sun Microsystems }\end{array}$ \\
\hline Sep 1998 & $\begin{array}{l}\text { Google Inc. was incorporated at a friend's garage in Menlo Park, California. A fellow Ph.D. student, Craig } \\
\text { Silverstein, was hired as the first employee }\end{array}$ \\
\hline Dec 1998 & $\begin{array}{l}\text { Google indexes about } 60 \text { million pages. 'PC Magazine' names Google as the 'search engine of choice' for } \\
1998 .\end{array}$ \\
\hline Jun 2000 & $\begin{array}{l}\text { Partnership agreement with Yahoo! to become its default search provider. Google indexes more than } 1 \\
\text { billion web pages. }\end{array}$ \\
\hline Oct 2000 & Google AdWords launches with 350 customers. \\
\hline $\begin{array}{l}\text { May } 2000- \\
\text { Aug } 2001\end{array}$ & Dot Com Bubble Burst \\
\hline Aug - Sep 2001 & 'Project Caribou' kick-off. Used JavaScript + xmlHTTPRequest for building the email application. \\
\hline Mar 2003 & $\begin{array}{l}\text { Google announces a new content-targeted advertising service - a spin-off product from 'Project Caribou' - } \\
\text { - that lets publishers access Google's vast network of advertisers. }\end{array}$ \\
\hline Apr - Jun 2003 & $\begin{array}{l}\text { Google acquires Applied Semantics. Integrates the 'content-targeted' advertising service (i.e. 'AdSense for } \\
\text { Content') with the technology from Applied Semantics to start a new advertisement service named, } \\
\text { 'AdSense'. }\end{array}$ \\
\hline April, 2004 & $\begin{array}{l}\text { Google's press release on a new email service with 1GB storage, with no pop-up and banner Ads, and with } \\
\text { no 'delete button'. }\end{array}$ \\
\hline Aug 2004 & Google IPO. \\
\hline Oct 2004 & $\begin{array}{l}\text { First Web } 2.0 \text { Conference organized by Tim O'Reilly. First signs of revival for the 'internet industry' after } \\
\text { the Dot Com Bubble burst. }\end{array}$ \\
\hline April, 2005 & $\begin{array}{l}\text { Exactly one year after the initial release, Gmail increased mailbox size to } 2 \mathrm{~GB} \text {, advertising it as } 2 \mathrm{~GB} \text { plus, } \\
\text { and introduced some other new features, including formatted editing which gave users the option of } \\
\text { sending messages in HTML or plain text. }\end{array}$ \\
\hline April 2005 & $\begin{array}{l}\text { Gmail became available in several languages: British English, Dutch, French, German, Italian, Japanese, } \\
\text { Korean, Portuguese, Spanish, Russian and simplified and traditional Chinese. }\end{array}$ \\
\hline May 2005 & Google launches Google Web Toolkit (GWT) for developing AJAX-based web applications \\
\hline Aug 2005 & Gmail started offering 100 invitations to some users. \\
\hline Dec 2005 & $\begin{array}{l}\text { Google released a version of Gmail for mobile devices, providing phone interface access through } \\
\text { http://m.gmail.com, named 'Gmail Mobile'. }\end{array}$ \\
\hline Jan 2006 & Gmail added a delete button to the menu bar. \\
\hline Apr 2006 & $\begin{array}{l}\text { Gmail was integrated into the newly released Google Calendar service. } \\
\text { World Wide Web Consortium (W3C) releases the first draft specification for the XMLHttpRequest object } \\
\text { in an attempt to create an official web standard. }\end{array}$ \\
\hline Dec 2006 & Google open-sources the GWT toolkit. Starts a series of initiatives aimed at sponsoring AJAX. \\
\hline Jan 2007 & $\begin{array}{l}\text { Google Docs and Spreadsheets is integrated with Gmail, providing the capability to open attached } \\
\text { Microsoft Word DOC files directly from Gmail. }\end{array}$ \\
\hline Feb 2007 & Gmail registration is opened to the public. However, still remains in beta. \\
\hline Jun 2008 & Introduces Gmail Labs. \\
\hline Jul 2009 & Gmail moves out of its 'beta' status. \\
\hline
\end{tabular}




\section{TABLE 3: MECHANISMS ENABLING IDENTITY-CHALLENGING INNOVATIONS AT GOOGLE}

\begin{tabular}{|c|c|c|}
\hline Illustrative Quotes & Themes & $\begin{array}{l}\text { Theoretical } \\
\text { Mechanisms }\end{array}$ \\
\hline $\begin{array}{l}\text { '...if you want innovation, it's critical that people are able to work on ideas that are unapproved and generally thought to } \\
\text { be stupid.' (Buchheit, 2009a) 'Ideas can spring from someone trying to solve a problem in their own life. Engineer } \\
\text { Krishna Bharat found himself consumed with reading news about } 9 / 11 \text {. Everyday he'd log on to the same } 15 \text { news sites } \\
\text { and read stories about, say, anthrax, to get different perspectives. To make it easier for himself, he created a tool that } \\
\text { would gather the news from a bunch of sources and cluster them together. He passed the tool along to fellow Googlers to } \\
\text { use and someone said, 'Hey, this might be great for our users.” Voila: Google News.' (Marissa Mayer, as quoted in } \\
\text { Kalyn, 2008) }\end{array}$ & $\begin{array}{l}\text { Explore novel } \\
\text { ideas during work }\end{array}$ & \multirow[t]{5}{*}{$\begin{array}{l}\text { Reflection- } \\
\text { through- } \\
\text { action }\end{array}$} \\
\hline $\begin{array}{l}\text { "new projects should be spawned by whoever has the best ideas, not who is in what place in the hierarchy, and the culture } \\
\text { is based on this fundamental_belief" (Berkun, 2008) }\end{array}$ & & \\
\hline $\begin{array}{l}\text { "We try things. Remember, we celebrate our failures. This is a company where it's absolutely okay to try something } \\
\text { that's very hard, have it not be successful, and take the learning from that." (Eric Schmidt talking about the failure of } \\
\text { much-talked about product 'Google Wave' at the Techonomy'2010 Conference in Lake Tahoe, CA) }\end{array}$ & & \\
\hline $\begin{array}{l}\text { "We didn't want to simply bolt new features onto old interfaces. We needed to rethink email, but at the same time we } \\
\text { needed to respect that email already had over } 30 \text { years of history, thousands of existing programs, and nearly a billion } \\
\text { users. So we started by learning which features were most important, and which problems were most aggravating." } \\
\text { (Buchheit, 2005) }\end{array}$ & $\begin{array}{l}\text { Talk-back/Back- } \\
\text { talk }\end{array}$ & \\
\hline \multicolumn{2}{|l|}{$\begin{array}{l}\text { "We were pretty nervous about some of our features. The idea of doing the whole thing in JavaScript-internally a lot of } \\
\text { people were very unsure about that, but I think that our users loved it. It actually worked better than we expected it to. We } \\
\text { were pretty nervous about it, because there are so many browsers out there and they all have plug-ins and some of these } \\
\text { plug-ins will cause problems for you. It's really worked out better than we thought it would." (Buchheit, as quoted in } \\
\text { Livingston, 2007) }\end{array}$} & \\
\hline $\begin{array}{l}\text { "Google engineers prototype new applications on the platform; if any of these begin to get users' attention, developers } \\
\text { can launch beta versions to see whether the company's vast captive customer base responds enthusiastically. Such a } \\
\text { review would be the province of top executives, the marketing department, or an executive committee." (Iyer and } \\
\text { Davenport, 2008) }\end{array}$ & $\begin{array}{l}\text { Fast } \\
\text { experimentation } \\
\text { to illustrate proof- } \\
\text { of-concept }\end{array}$ & Prototyping \\
\hline $\begin{array}{l}\text { "Prototyping new ideas, especially bad ideas, as fast and easy as possible. This can be especially difficult as a product } \\
\text { grows... Of course none of the code from my prototype ever made it near the real product (thankfully), but that code did } \\
\text { something that fancy arguments couldn't do (at least not my fancy arguments), it showed that the idea and product had } \\
\text { real potential." (Buchheit, 2009a) }\end{array}$ & & \\
\hline
\end{tabular}




\begin{tabular}{|c|c|c|}
\hline $\begin{array}{l}\text { 'We like to put products out there early, see what users say about them, find out about additional features they'd like to } \\
\text { see, and then build those out. We anticipate that we're going to throw out a lot of products.' (Marissa Mayer, as quoted in } \\
\text { Kalyn, 2008) } \\
\text { '.... It was easy for me to stuff random broken features into Gmail when there were only about } 100 \text { users and they all } \\
\text { worked for Google, but it's not so simple when there are } 100 \text { million users. Fortunately for Gmail, they've recently found } \\
\text { a rather clever solution that enables the thousands of Google engineers to add new UI features: Gmail Labs.' (Buchheit, } \\
2009 \text { a) }\end{array}$ & Probe and Learn & \\
\hline $\begin{array}{l}\text { "Literally from day one, we had users internally. One nice thing about Google is that we can just release things internally } \\
\text { and have this great population of testers, essentially... The great thing about this process was that I didn't need to sell } \\
\text { anyone on my ideas. I would just write the code, release the feature, and watch the response. From that day until launch, } \\
\text { every new feature went live immediately, and most new ideas were implemented as soon as possible" (Buchheit, 2009a) } \\
\text { "“... But when the thing you really want to work on is to make a broad change across the whole organization, you need } \\
\text { something new - you need a 'grouplet'... In addition to the efforts of our professional quality assurance team, we have } \\
\text { the Fixit grouplet, which coordinates special Fixit days when it tries to have our engineers focus on solving one class of } \\
\text { problems. Sometimes we have Documentation Fixits, when we try to catch up on all the internal documentation that we } \\
\text { shave let slide... These grouplets have practically no budget, and they have no decision-making authority. What they have } \\
\text { is a bunch of people who are committed to an idea and willing to work to convince the rest of the company to adopt it. } \\
\text { Consider the collection of engineers who wanted to promote 'agile programming' inside the company. Agile } \\
\text { programming is a product development approach that incorporates feedback early and often, and was being done in a few } \\
\text { scattered parts of the organization... The Agile grouplet formed to try to take this idea and spread it throughout the } \\
\text { organization. It did so by banding together and reaching out to as many groups as it could to teach the new process. It } \\
\text { created 'Agile Office Hours' when you could stop by and ask questions about the process. It handed out books and gave } \\
\text { internal talks on the topic. It attended staff meetings and created the concept of the 'Agile Safari,' in which you could } \\
\text { volunteer to work for a time in groups that were using Agile, to see how it ticks.” (Mediratta, 2007) }\end{array}$ & $\begin{array}{l}\text { Demonstration of } \\
\text { nascent ideas to } \\
\text { others }\end{array}$ & \multirow[t]{4}{*}{$\begin{array}{l}\text { Collective } \\
\text { Engagement }\end{array}$} \\
\hline $\begin{array}{l}\text { "The intranet in Google is super transparent. Teams are actively encouraged to share the most intimate details of their } \\
\text { projects with the rest of the company. This happens through tech talks, design docs, lunch table conversations, etc. When } \\
\text { two teams are doing similar things, people start with the assumption that they must have their reasons and that the } \\
\text { situation will be worked out in time. There isn't a huge push to over optimize and have only one solution for each } \\
\text { problem. This means that there isn't an adversarial relationship between teams that can lead to long standing animosities } \\
\text { and information hiding." (Beda, 2005) }\end{array}$ & $\begin{array}{l}\text { Facilitating } \\
\text { recombination of } \\
\text { ideas }\end{array}$ & \\
\hline $\begin{array}{l}\text { "Creativity comes out of people bumping into each other and not knowing where to go." (Laszlo Bock, Head of personnel } \\
\text { at Google, as quoted in Hamel and Breen, 2007) }\end{array}$ & & \\
\hline $\begin{array}{l}\text { "There is, by and large, only one codebase at Google. This has many advantages. Most obvious is that it is really easy to } \\
\text { look at and contribute to code in other projects without having to talk to anyone, get special permissions or fill out forms } \\
\text { in triplicate. That is just the tip of the iceberg, though. Having one codebase means that there is a very high degree of } \\
\text { code sharing. Need to base } 64 \text { encode/decode something? No problem, there is a standard Google routine for that." (Beda, } \\
\text { 2005) }\end{array}$ & & \\
\hline
\end{tabular}


FIGURE 1: ENABLING IDENTITY-CHALLENGING INNOVATIONS THROUGH AN IDEOLOGY OF PARTICIPATIVE EXPERIMENTATION

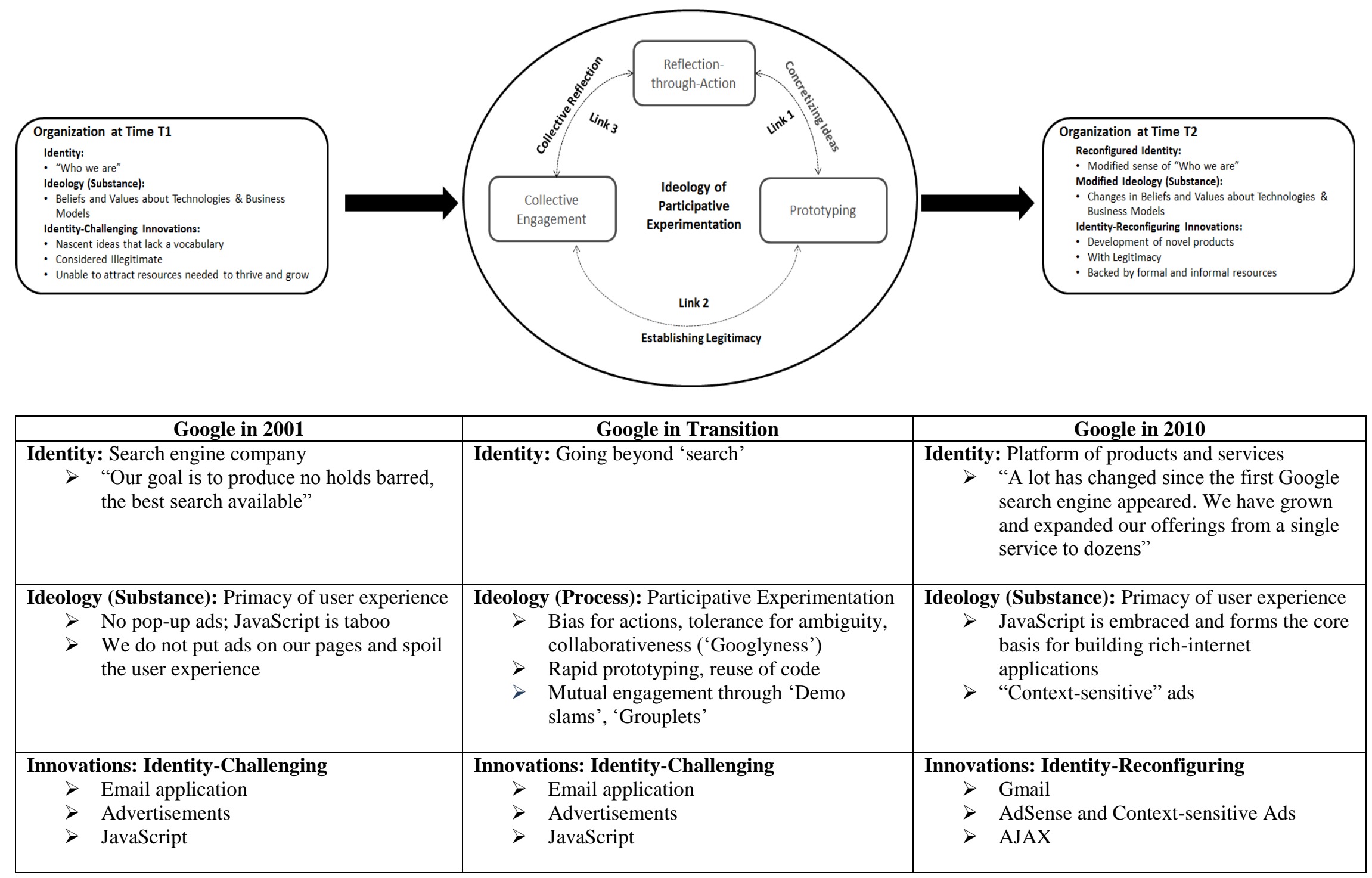




\section{AUTHOR BIOS (150 words):}

Raghu Garud is Alvin H. Clemens Professor of Management \& Organization and the Research Director of the Farrell Center for Corporate Innovation and Entrepreneurship, Pennsylvania State University. His research explores the emergence of novelty and its adoption. Specifically, he is interested in understanding how new ideas emerge, are valued, and become institutionalized. Raghu is currently working on Managing in the Age of Disruptions.

Arvind Karunakaran is a Ph.D. student at MIT Sloan School of Management. His research examines how and in what ways do novel digital technologies (e.g., cloud computing, predictive analytics) and organizational forms (e.g., platform organizations) create uncertainties in the workplace, how they shape identities, power relations, and coordination, and the implications these produce for organizational and occupational change. He is a Fellow at the Christian Regenhard Center for Emergency Response Studies, New York. For his research, he was awarded the University of Chicago Ethnography Fellowship, Dissertation Scholar Award by the Strategy Research Foundation, Donald R. Cressey Award for the Most Outstanding Research Project by the Horowitz Foundation for Social Policy, Vincent Cerf Award for the Best Student Paper for Design Research, the MIT Energy Fellowship, and the Design Management Institute Research Scholarship. 